\section{Contrast-enhanced ultrasound of hepatocellular carcinoma: where do we stand?}

\author{
Tommaso Vincenzo Bartolotta, Adele Taibbi, Massimo Midiri, Roberto Lagalla \\ Department of Radiology, University of Palermo, Palermo, Italy
}

Contrast-enhanced ultrasound (CEUS) represents a significant breakthrough in ultrasonography (US), and it is being increasingly used for the evaluation of focal liver lesions (FLLS). CEUS is unique in that it allows non-invasive assessment of liver perfusion in real time throughout the vascular phase, which has led to dramatic improvements in the diagnostic accuracy of US in the detection and characterization of FLLs, the choice of therapeutic procedures, and the evaluation of response. Currently, CEUS is included as a part of the suggested diagnostic work-up of FLLs, including in cirrhotic patients with hepatocellular carcinoma, resulting in better patient management and cost-effective delivery of therapy.

Keywords: Contrast-enhanced ultrasonography; Hepatocellular carcinoma; Ultrasound contrast media; Liver; Ultrasonography; Liver cirrhosis

\section{Introduction}

Hepatocellular Carcinoma: The Burden

Hepatocellular carcinoma (HCC) is the sixth most common tumor worldwide and the fourth most common cause of cancer-related death [1]. Hepatitis B virus and/or hepatitis C virus infection, alcohol, and nonalcoholic fatty liver disease are the most predominant risk factors for HCC worldwide [2]. Patients with cirrhosis are considered a particularly high-risk group for developing HCC, prompting several international scientific societies to publish guidelines recommending surveillance of adults with cirrhosis based on evidence of improved overall survival [3-12]. The suggested surveillance tool for early detection of HCC is ultrasonography (US), usually performed every 6 months, with or without an a-fetoprotein serum assay.

Once HCC is suspected in a patient with cirrhosis, diagnostic imaging is recommended for confirmatory diagnosis and radiological staging. In particular, many international guidelines recommend a diagnostic evaluation for HCC using either multiphasic computed tomography (CT) or multiphasic magnetic resonance imaging (MRI) because both modalities show similar diagnostic performance [3]. Regardless of the particular strengths and shortcomings of each technique, both $\mathrm{CT}$ and MRI require contrast agents, the use of which can be problematic in patients with severely impaired renal function $[13,14]$.

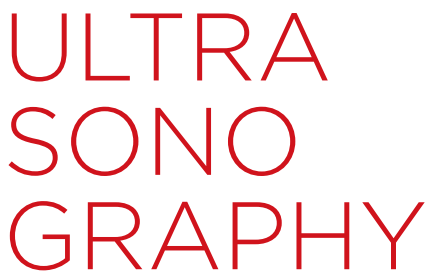

\section{REVIEW ARTICLE}

https://doi.org/10.14366/usg. 18060 pISSN: 2288-5919 • eISSN: 2288-5943 Ultrasonography 2019;38:200-214

Received: October 23, 2018

Revised: February 9, 2019

Accepted: February 25, 2019

Correspondence to:

Tommaso Vincenzo Bartolotta, MD, PhD, Department of Radiology, University of Palermo, Via Del Vespro 127, 90129 Palermo, Italy

Tel. +39-91-6552330

Fax. +39-91-6552337

E-mail: tommasovincenzo.bartolotta@ unipa.it

This is an Open Access article distributed under the terms of the Creative Commons Attribution NonCommercial License (http://creativecommons.org/ licenses/by-nc/4.0/) which permits unrestricted noncommercial use distribution, and reproduction in any medium, provided the original work is properly cited.

Copyright (C) 2019 Korean Society of Ultrasound in Medicine (KSUM)

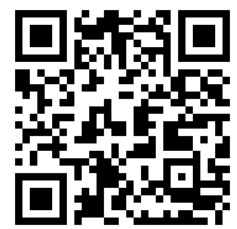

How to cite this article:

Bartolotta TV, Taibbi A, Midiri M, Lagalla $R$. Contrast-enhanced ultrasound of hepatocellular carcinoma: where do we stand? Ultrasonography. 2019 Jul;38(3):200214. 


\section{Contrast-Enhanced Ultrasound}

Despite technical advances in both spatial and contrast resolution, gray-scale US is still considered a non-specific technique for the diagnosis of focal liver lesions (FLLs) [15]. Doppler examination may provide some clues to the diagnosis; for example, a spoke-wheel pattern associated with the arterial waveform in a pulsed Doppler evaluation may be highly suggestive, although not pathognomonic, of focal nodular hyperplasia in otherwise healthy young women taking oral contraceptives [16]. Nevertheless, Doppler examinations can only assess large vessels (i.e., $>100 \mu \mathrm{m}$ ), and Doppler US is prone to motion artifacts.

In the late 1990s, the introduction of microbubble-based contrast agents, along with contrast-specific gray-scale US techniques, led to a better depiction of microcirculation (i.e., vessels as thin as 40 $\mu \mathrm{m})$. Contrast-enhanced ultrasound (CEUS) enabled an accurate depiction of both macrocirculation and microcirculation, which was immediately exploited for the detection and characterization of FLLS, with reported sensitivity and specificity values approaching those of CT and MRI $[17,18]$.

CEUS is a real-time dynamic imaging technique, which enables the use of US to assess the contrast-enhancement patterns of FLLS in real time, without ionizing radiation and with a much higher temporal resolution than is possible with CT and MRI [19]. The examination is performed by injecting intravenously microbubblebased contrast agents (USCAs) consisting of gas bubbles with a radius ranging from 1 to $10 \mu \mathrm{m}$, presenting flexible shells (e.g., phospholipids) that are filled with low-solubility gases (e.g., perfluoropropane, perfluorocarbon, or sulfur hexafluoride) [20]. When injected intravenously, microbubble-based contrast agents pass through the pulmonary filter and remain within the

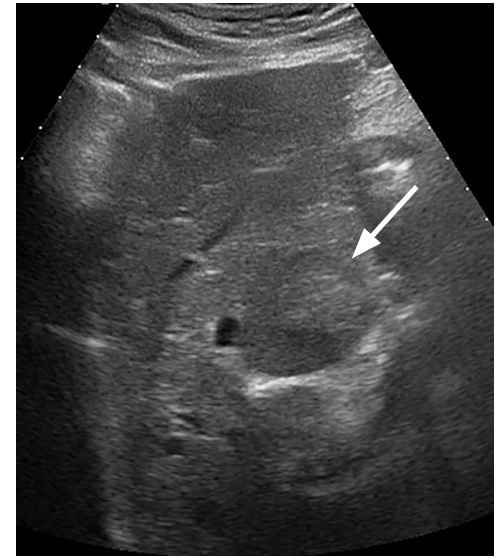

A

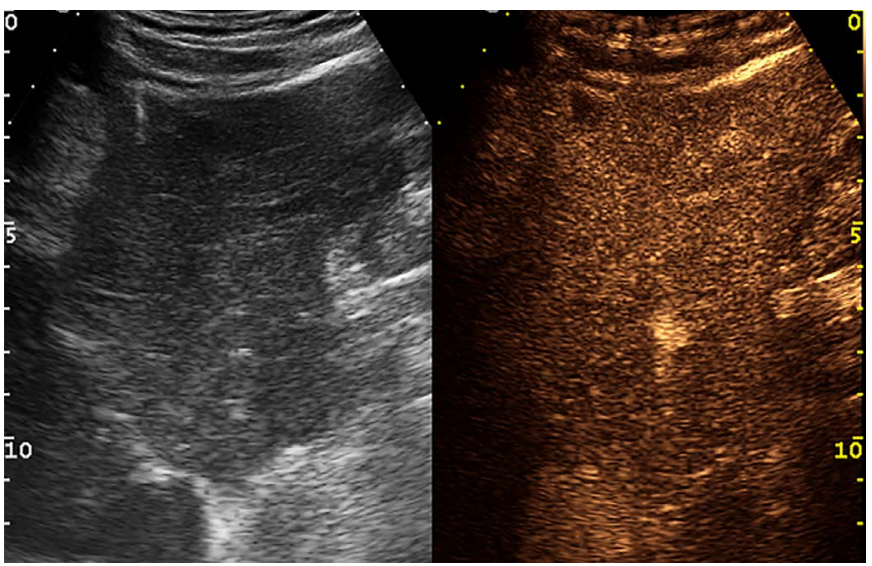

C

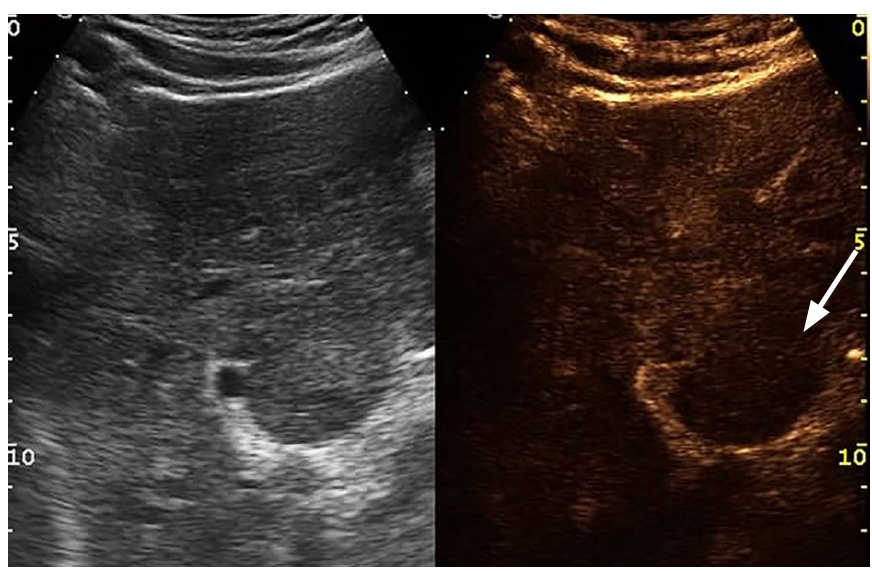

B

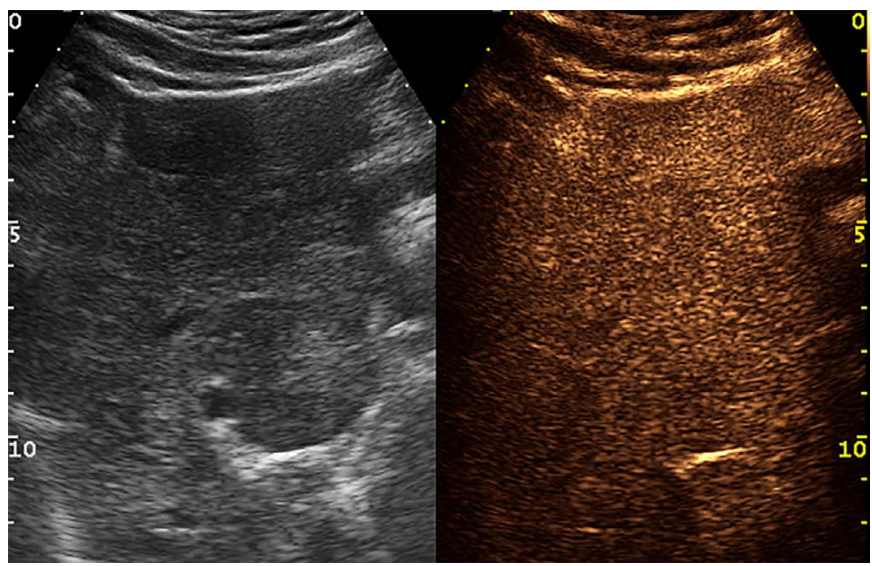

D

Fig. 1. Regenerative nodule in a 72-year-old man with cirrhosis.

A. Oblique ascending left subcostal baseline image reveals a moderately heterogeneous lesion measuring $3 \mathrm{~cm}$ in the fourth hepatic segment (arrow). B. In an image obtained 22 seconds after sulfur hexafluoride injection (arterial phase), the lesion lacks contrast enhancement (arrow). C, D. The lesion appears consistently isoechoic with respect to the surrounding liver parenchyma throughout the remaining vascular phases. 
intravascular space (blood-pool agents), where they act as purely vascular tracers (blood markers).

Some USCAs also present a post-vascular phase in the liver and spleen, where they can be trapped in the liver sinusoids or may be selectively taken up by phagocytic cells of the reticuloendothelial system [21]. USCAs are completely eliminated within 5 to 20 minutes after injection; the gas diffuses into the blood and is then exhaled via the lungs, while the shell components are metabolized by the liver or filtered by the kidney [22].

USCAs are generally safe and well tolerated. They are not nephrotoxic and may be used even in patients with renal failure, renal obstruction, or chronic obstructive pulmonary disease. It is not recommended to perform laboratory tests of renal function before administering them. In a multicenter study of 23,188 patients who had been examined for liver lesions, a serious adverse event rate of $0.0086 \%$ was reported, with no deaths and a lifethreatening anaphylactoid reaction rate of less than $0.002 \%$ [23]. By comparison, the incidence of serious adverse events is about $0.02 \%-0.1 \%$ after administration of non-ionic $X$-ray contrast agents and $0.005 \%-0.2 \%$ after administration of gadolinium chelates for MRI [24].

Currently, CEUS is included as a part of the suggested diagnostic work-up of liver FLLs, resulting in better patient management and cost-effective delivery of therapy [25]. The use of CEUS for this purpose is supported by a recent meta-analysis confirming that CEUS had excellent diagnostic capability for differentiating malignant from benign FLLs. In that study, the pooled sensitivity, specificity, diagnostic odds ratio, positive likelihood ratio, negative likelihood ratio, and area under the curve for CEUS in the characterization of FLLs were $92 \%, 87 \%, 104.20,7.38,0.09$, and

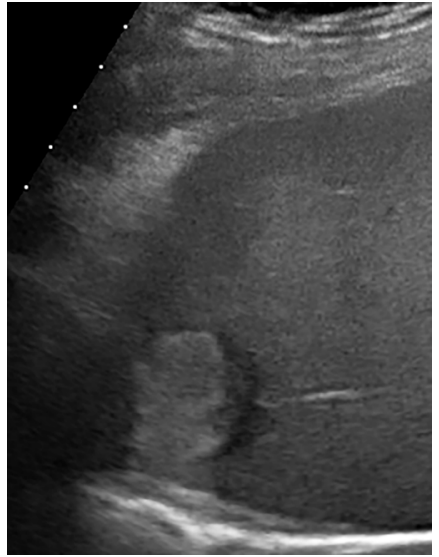

A

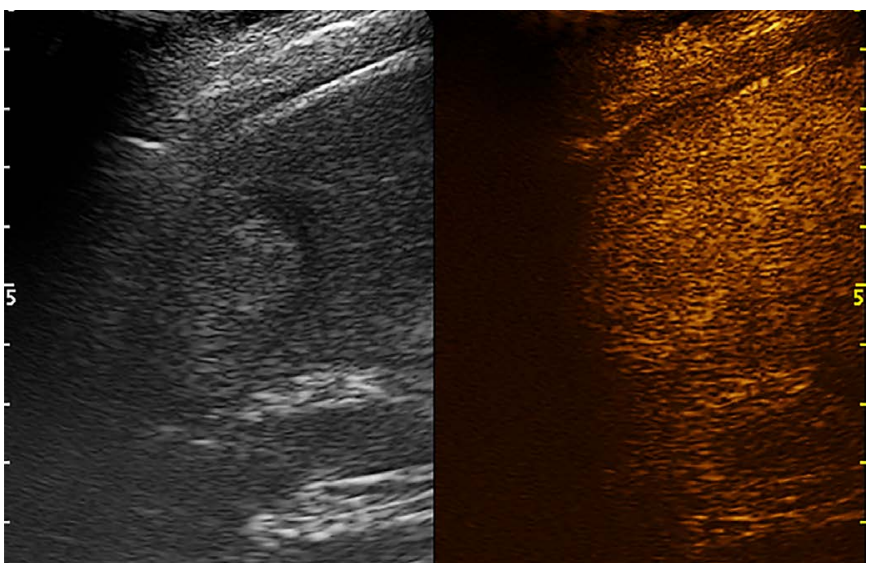

C

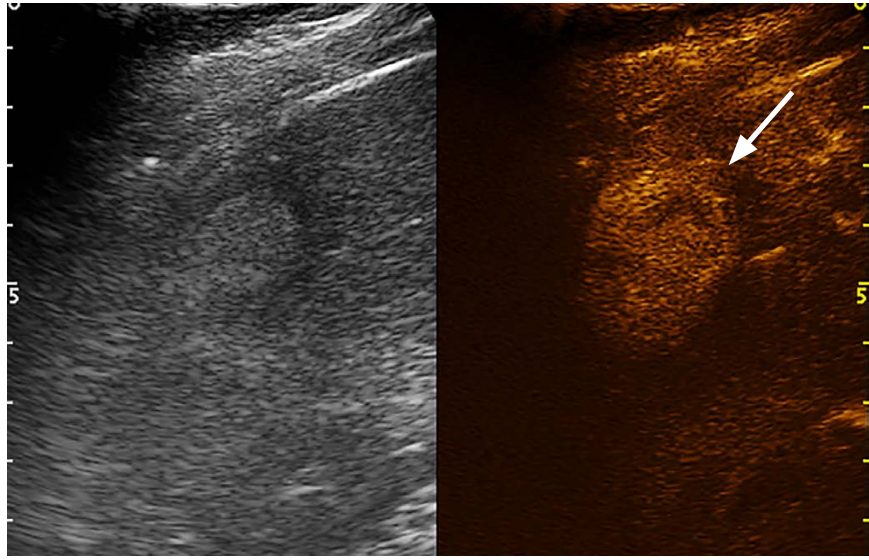

B

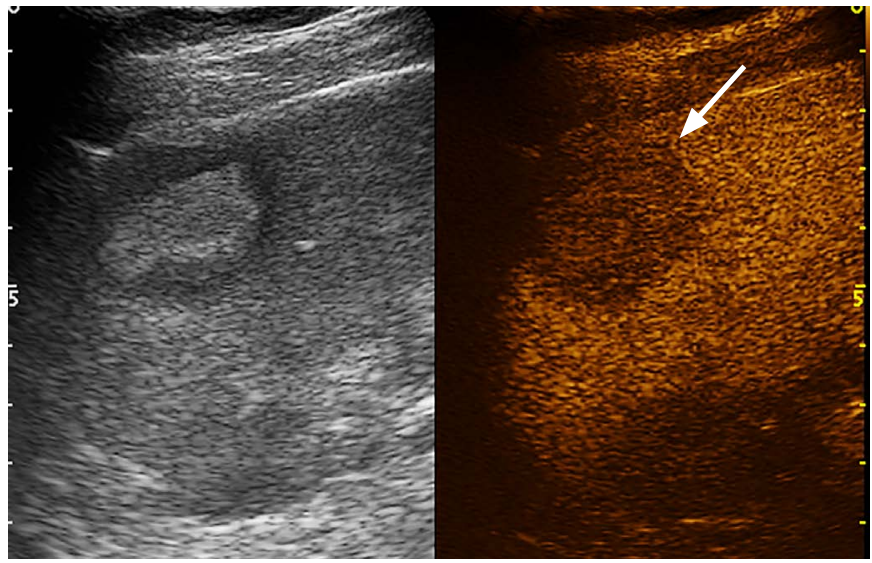

D

Fig. 2. Hepatocellular carcinoma in a 65-year-old woman with hepatitis C-related cirrhosis.

A. Oblique ascending right subcostal baseline image reveals a mainly hyperechoic lesion surrounded by a peripheral hypoechoic rim measuring $4 \mathrm{~cm}$ in the sixth hepatic segment (calipers). B. The lesion appears markedly hypervascular during the arterial phase (arrow). C, D. It is not appreciable 83 seconds after sulfur hexafluoride injection (C), and shows clear-cut washout at 240 seconds (arrow) (D). 


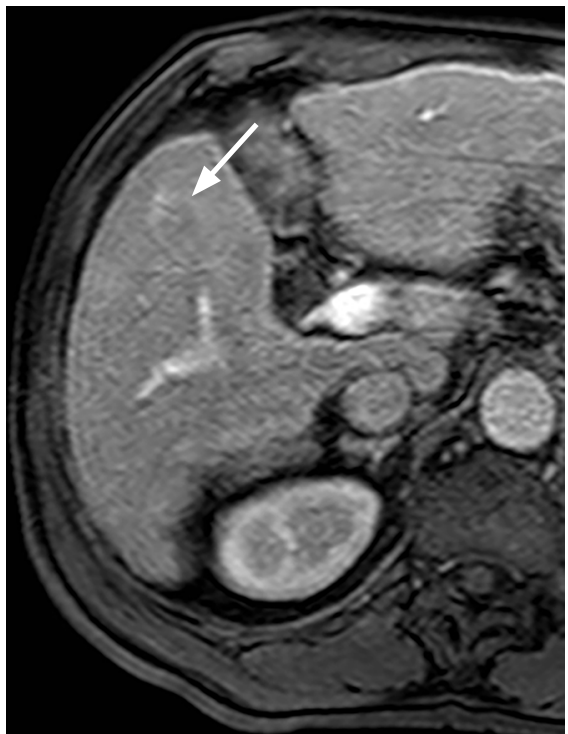

A

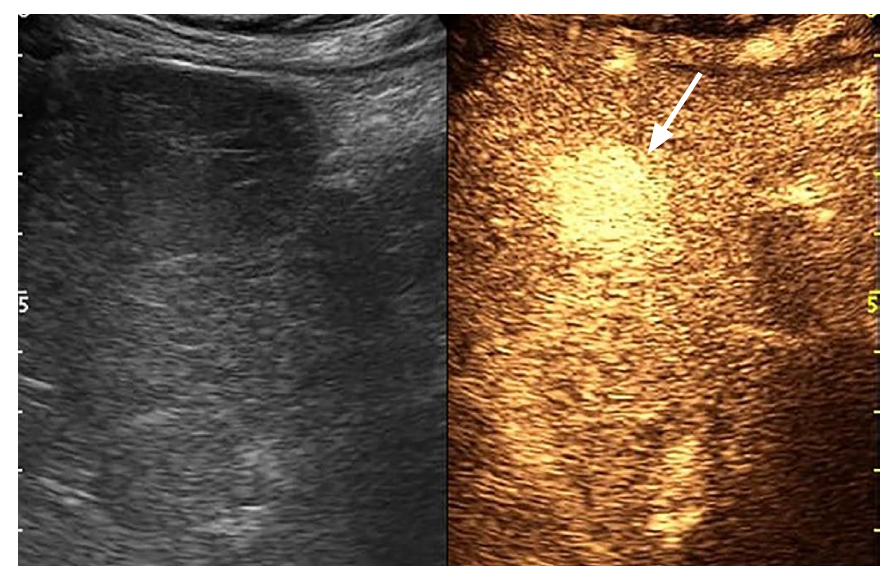

D

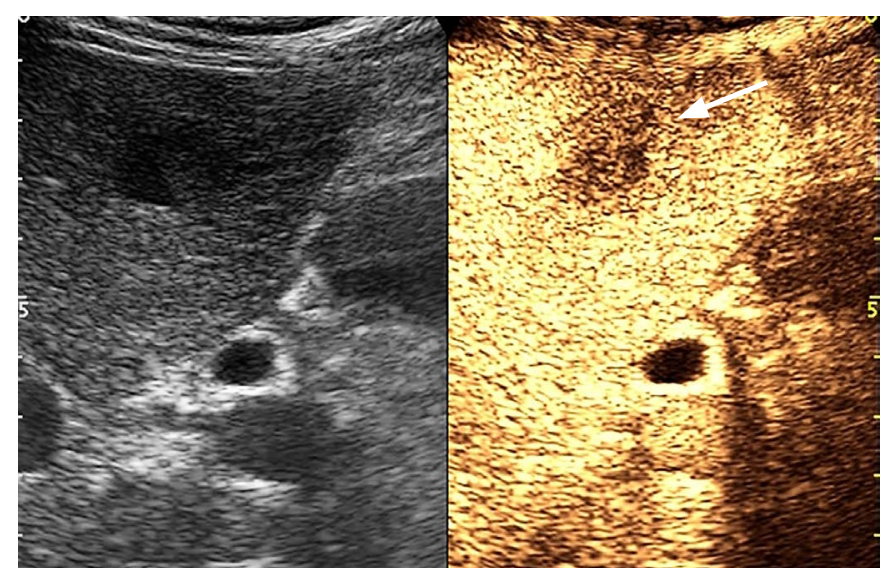

$\mathrm{F}$

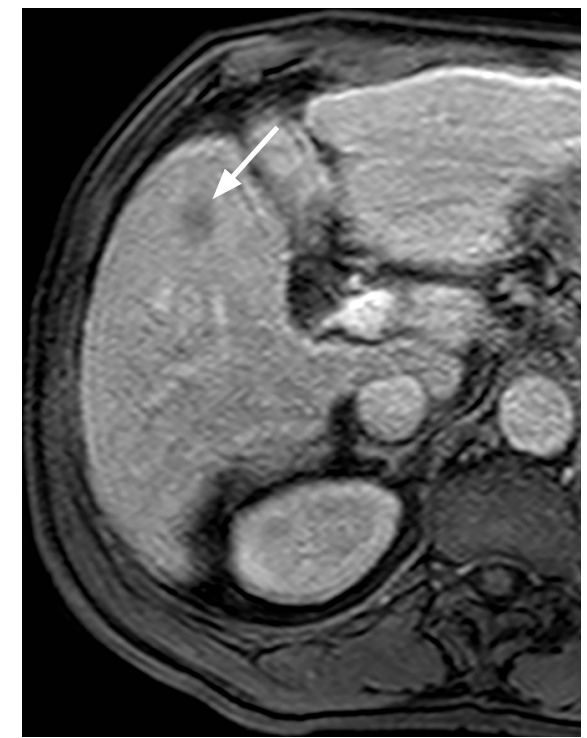

B

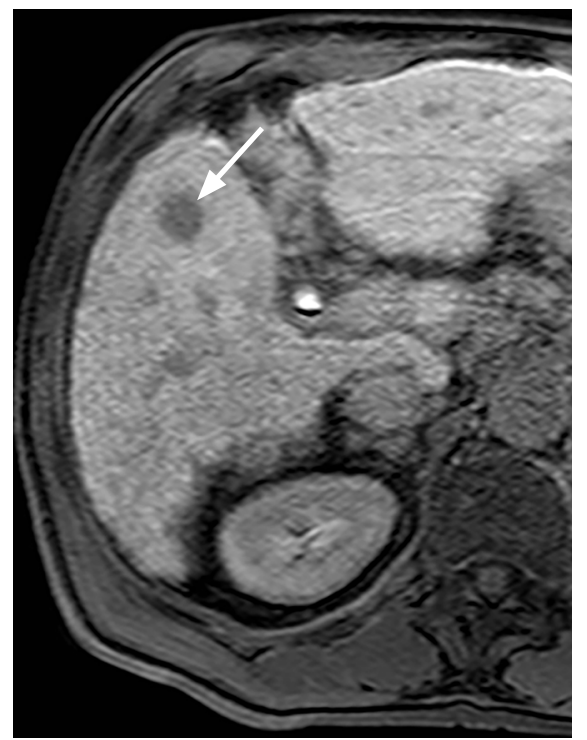

C

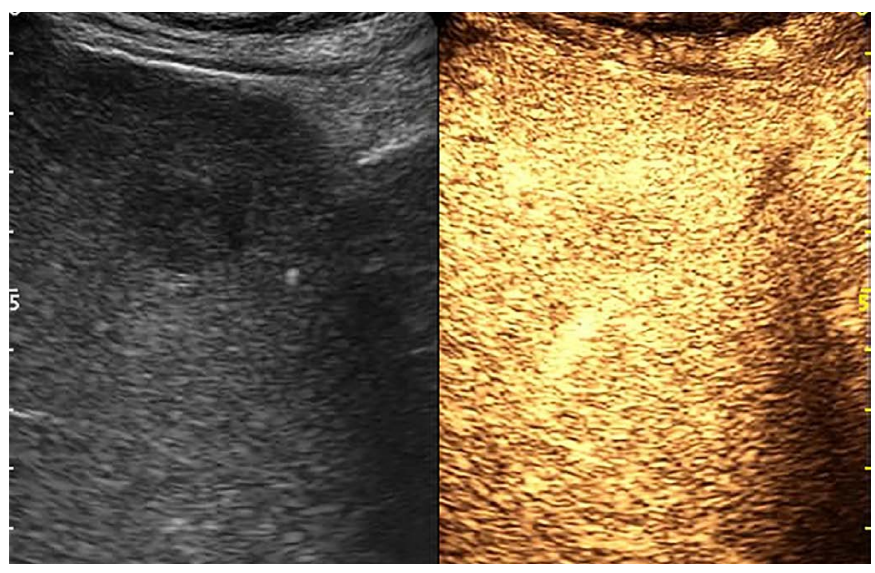

$\mathrm{E}$

Fig. 3. Hepatocellular carcinoma in a 53-year-old man.

A. A magnetic resonance image obtained during the hepatic arterial phase reveals a substantially unenhancing lesion in the fifth segment, measuring $1.5 \mathrm{~cm}$ (arrow). B, C. On magnetic resonance images obtained at same level during the portal venous (B) and the hepatocellular-specific (C) phases, the lesion appears hypointense (arrows). D-F. On contrast-enhanced ultrasonography, the same lesion is hypervascular on the image acquired during the arterial phase (arrow), is not evident during the extended portal-venous phase, but shows clear-cut washout (arrow) 300 seconds after sulfur hexafluoride injection (F). 


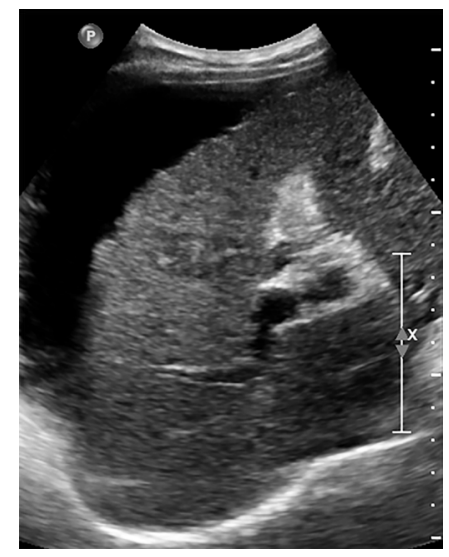

A

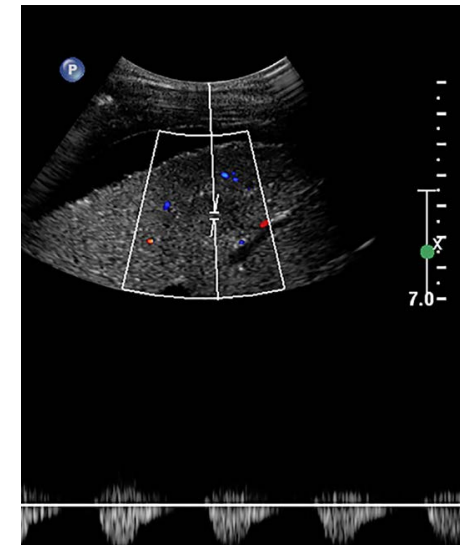

B

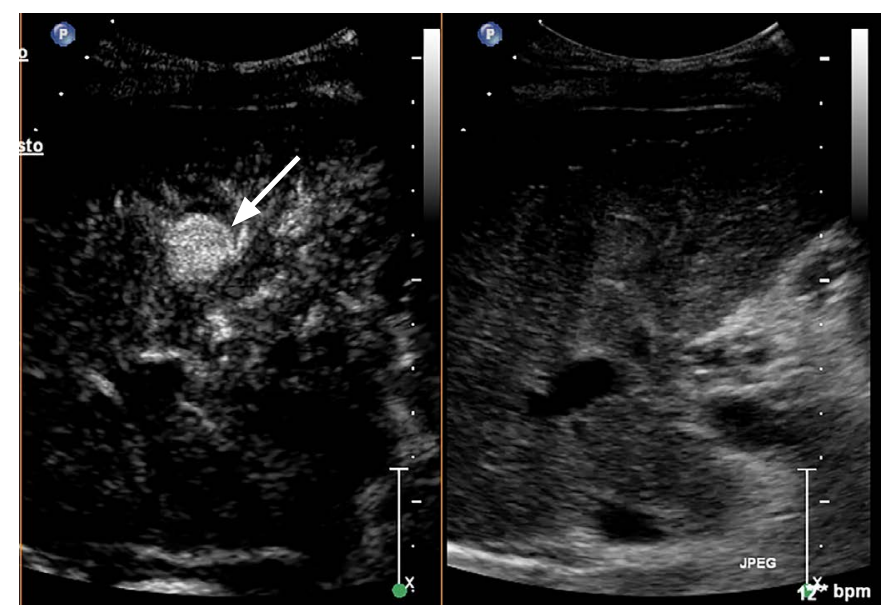

C

0.9665 , respectively [21].

\section{Technical Note}

The US technique used in the cases illustrated in this article consisted of continuous scanning performed by means of various ultrasound equipment: RS80A and RS85A with Prestige (Samsung Medison, Co. Ltd., Seoul, Korea), an iU22 unit (Philips Ultrasound, Bothell, WA, USA), and MyLab Twice (Esaote, Genova, Italy). All of these units are provided with multifrequency convex array probes and contrastspecific imaging software. A baseline survey examination, including a color/power and pulsed Doppler analysis, was always performed in order to choose the best acoustic window and plane to image the lesion. Once set, the US scan parameters-such as focal zone and time gain compensation-were not changed throughout the study. The US contrast agent used was a sulfur hexafluoride-filled microbubble-based contrast agent (SonoVue, Bracco, Milan, Italy), which was injected intravenously as a $2.4-\mathrm{mL}$ bolus (equivalent to $0.003 \mathrm{~mL} / \mathrm{kg}$ for $70 \mathrm{~kg}$ of body weight) followed by $5-10 \mathrm{~mL}$ of
Fig. 4. Well-differentiated hepatocellular carcinoma in a 58-year-old man.

A, B. A right intercostal baseline image reveals a hypoechoic lesion measuring $1.5 \mathrm{~cm}$ in the fifth hepatic segment (calipers) (A), with some small arterial vessels inside the lesion in the pulsed Doppler evaluation (B). C. The lesion appears markedly hypervascular 25 seconds after sulfur hexafluoride injection (arrow). D. The lesion is not evident during the late phase (240 seconds).

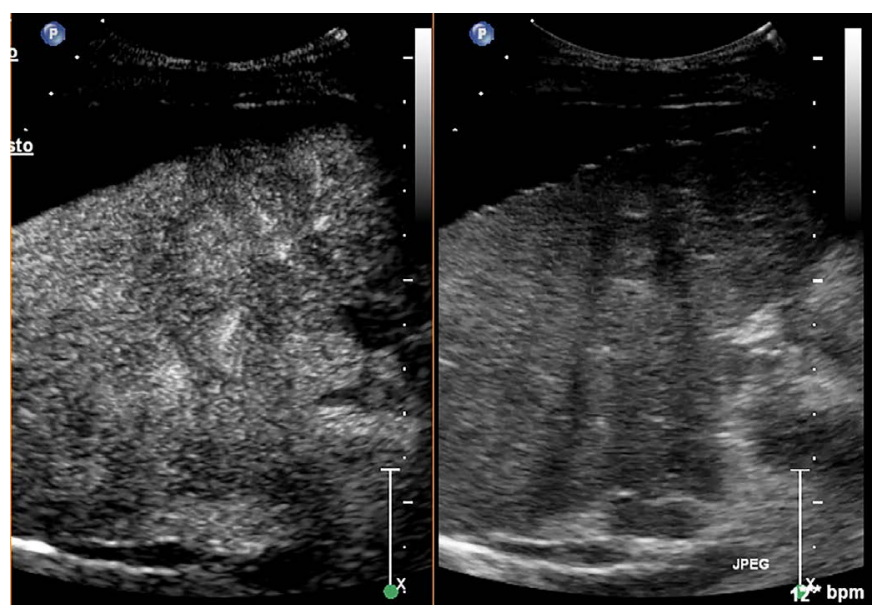

D

normal saline flush using a 20- or 22-gauge peripheral intravenous cannula. In order to minimize microbubble disruption, a low framerate $(5 \mathrm{~Hz})$ and a low mechanical index $(\mathrm{MI})$, ranging from 0.05 to 0.08 , were used for real-time imaging. One focus was positioned below the level of the lesion. Each examination lasted roughly 5 minutes after the bolus injection.

Digital cineloops were registered both during baseline and postcontrast US scanning in the arterial (i.e., 10-35 seconds from the start of the contrast agent bolus injection), portal venous (i.e., 5580 seconds from the start of the injection), and late (i.e., 235260 seconds from the start of the injection) phases. The baseline echogenicity and the dynamic enhancement pattern of each lesion in the arterial, portal-venous, and late phases in comparison with adjacent liver parenchyma were evaluated.

\section{HCC: CEUS Findings}

Through exploiting the progressive changes in the intranodular blood supply during the process of hepatocarcinogenesis, unlike 


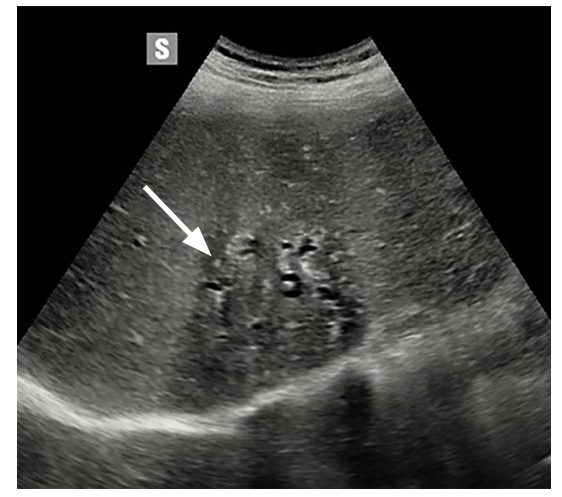

A
Fig. 5. Intrahepatic cholangiocarcinoma in a 73-year-old man.

A. An oblique ascending right subcostal baseline image reveals a highly heterogenous lesion with ill-defined margins measuring $6.5 \mathrm{~cm}$ in the eighth hepatic segment (arrow). B, C. During the arterial phase, the mass appears heterogeneously vascularized (arrow) (B) with rapid (43 seconds after sulfur hexafluoride injection) washout (arrow) (C). D. Arterial phase contrastenhanced computed tomography shows a hypoattenuating subcapsular mass (white arrow) associated with moderate bile duct dilatation in the context (black arrow). E, F. The lesion shows progressive enhancement during the portal-venous (E) and the late (F) phases (arrows).

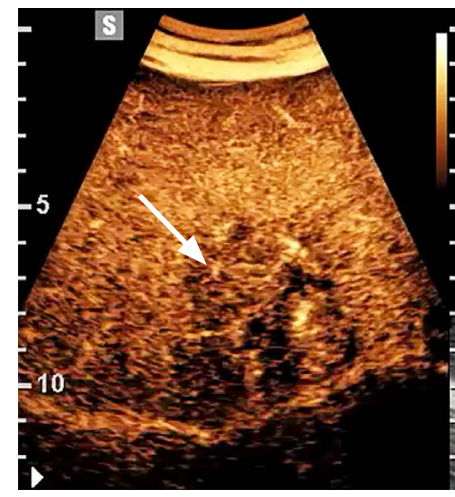

B
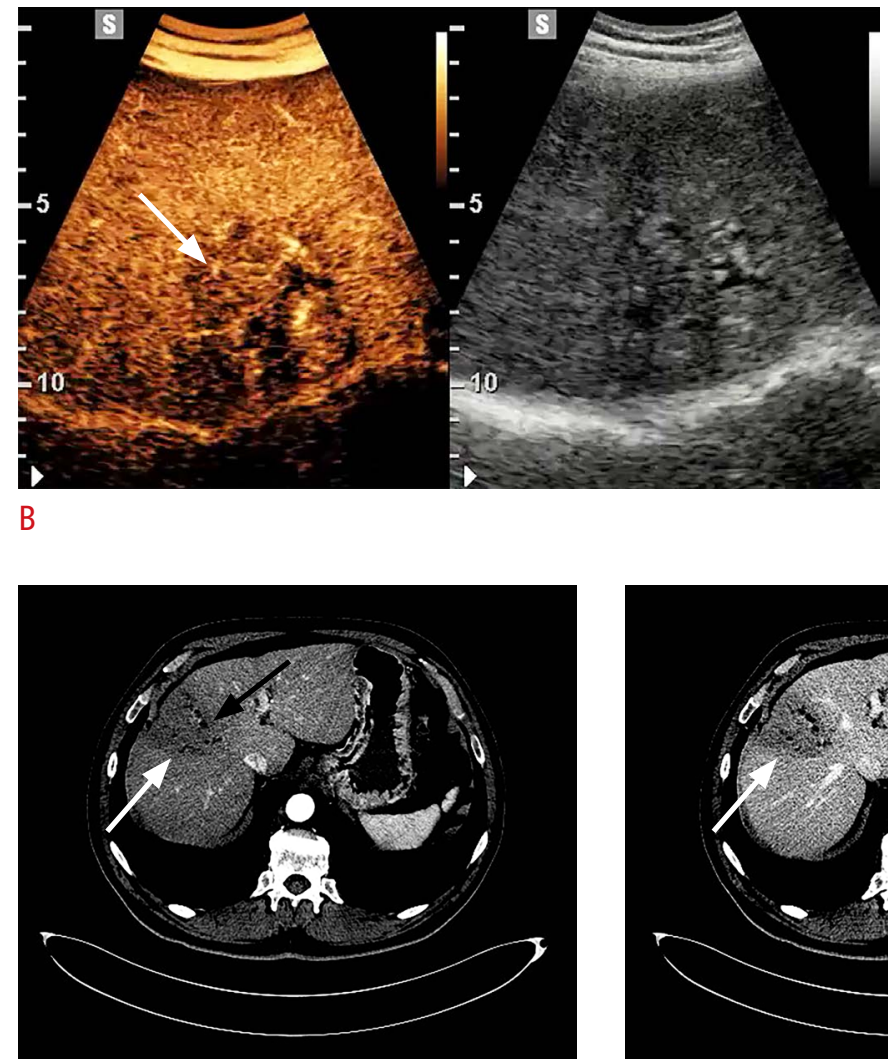

D

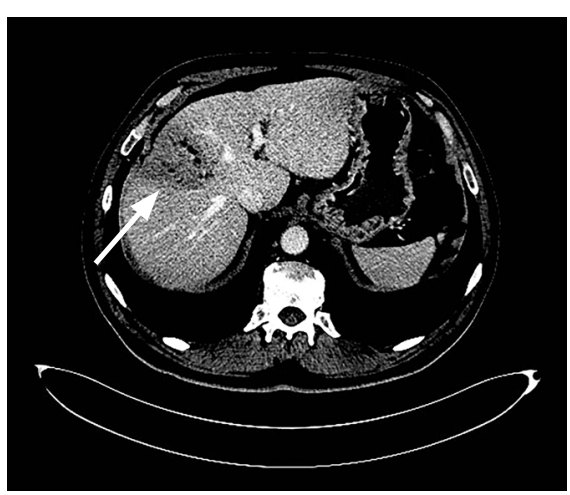

E

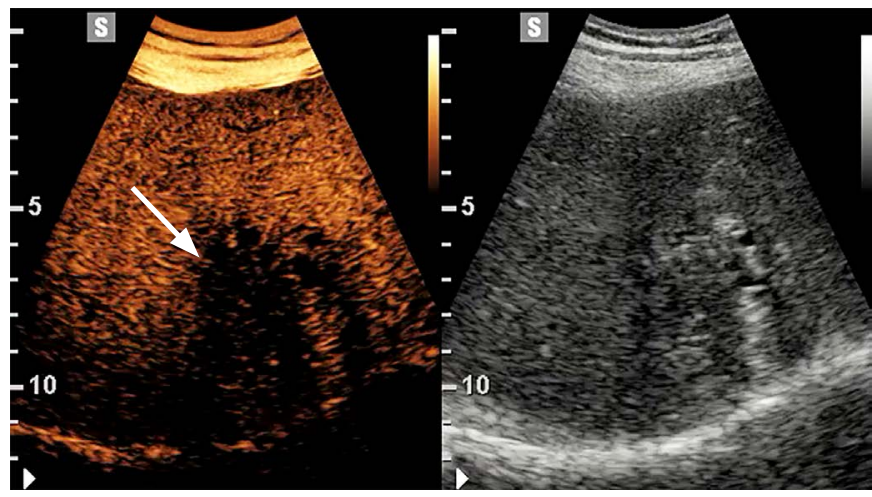

C

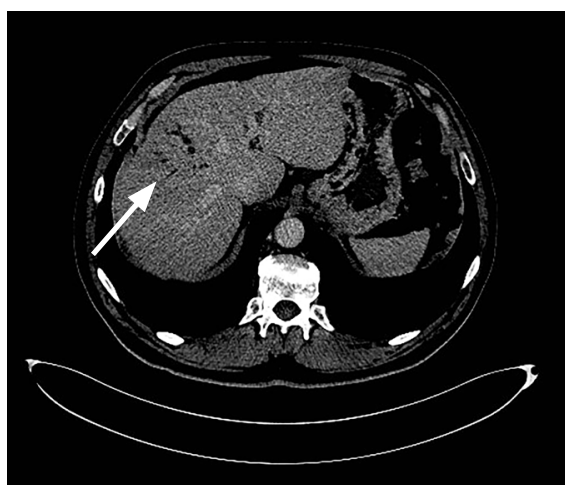

$\mathrm{F}$ what occurs in the development of many other solid tumors, the diagnosis of HCC can be non-invasively established by imaging without histopathologic confirmation [26].

Hepatocarcinogenesis is usually the result of a complex multistep process characterized by several key alterations at molecular, cellular, and histologic levels, including peculiar hemodynamic changes. Notably, during the step-wise progression from cirrhotic nodules through dysplastic nodules and early HCC to advanced HCC, portal tracts (which contain portal veins and nontumoral hepatic arteries) progressively diminish, whereas newly formed unpaired (nontriadal) arteries develop. Eventually, HCC is supplied mostly by the abnormal hepatic artery system [27].

As a consequence, cirrhotic nodules, also known as regenerative nodules (RNs), have a similar blood supply to the normal liver, and dysplastic nodules (DNs) are usually non-hypervascular. The vast majority of RNs and DNs are isoechoic to adjacent liver parenchyma during all phases on CEUS (Fig. 1) [28]. In contrast, HCC nodules are typically hyperenhanced in the arterial phase and show washout in the portal venous and delayed phases on contrast-enhanced multiphasic CT and MRI [29]. In this setting, CEUS is perfectly able 


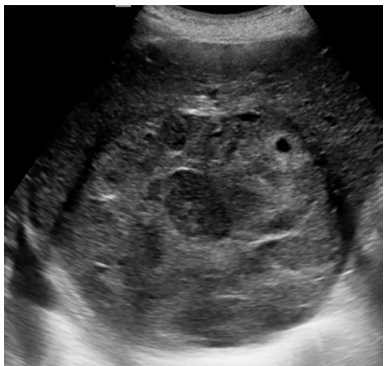

A

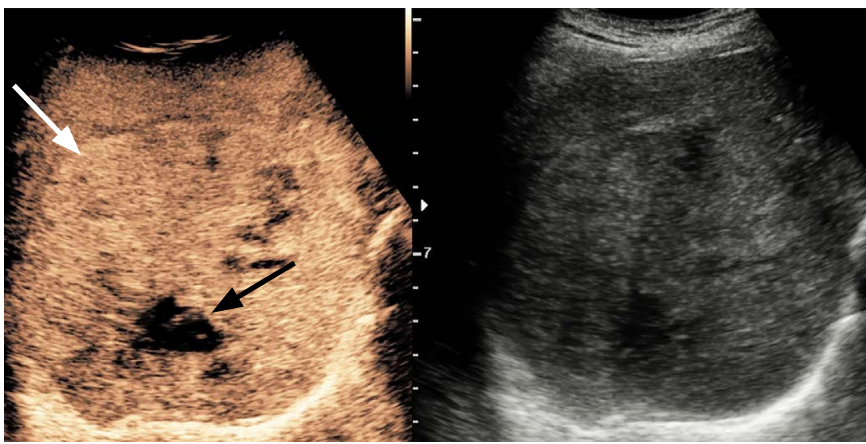

D

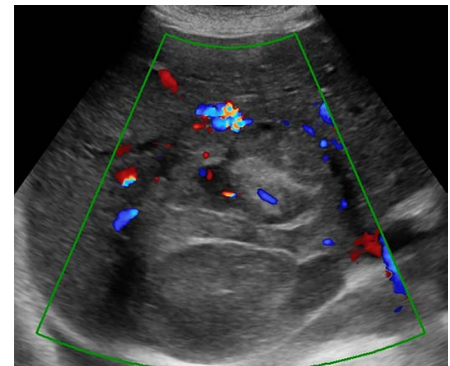

B

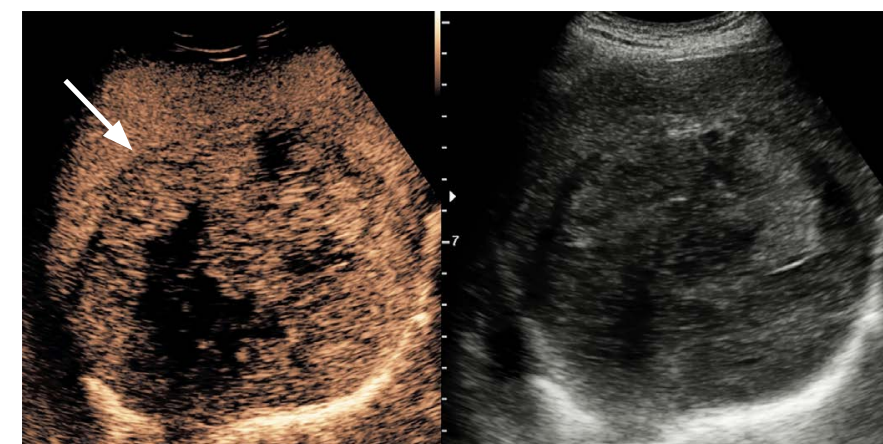

$\mathrm{E}$

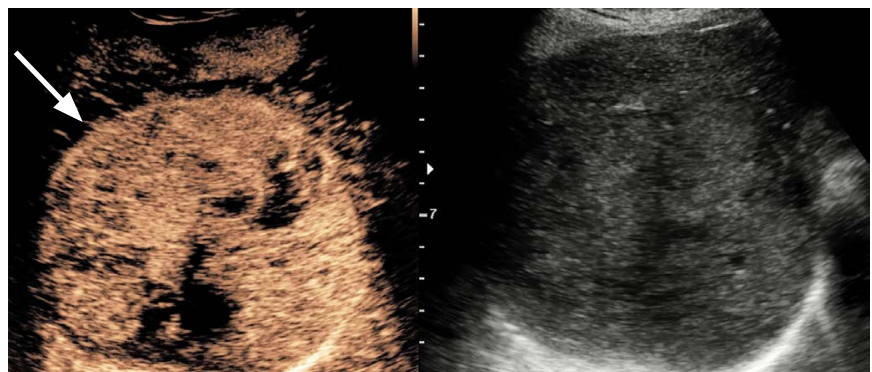

C

Fig. 6. Hepatocellular carcinoma in a 70-year-old man with hepatitis C-related cirrhosis.

A, B. An oblique ascending right subcostal baseline image reveals a markedly inhomogeneous lesion measuring $9.7 \mathrm{~cm}$ in the seventh hepatic segment (calipers) (A) with a vascular signal in its context (B). C. During the arterial phase, the mass is highly hypervascular (arrow). D. During the extended portal-venous phase, a slight hyperechoic peripheral rim is evident, suggesting a pseudocapsule (white arrow) with necrotic areas inside the mass (black arrow). E. The lesion shows a washout sign, appearing hypoechoic with respect to the surrounding liver parenchyma 5 minutes after the start of the hexafluoride injection (arrow).

to depict the typical contrast-enhancement pattern of arterial-phase hypervascularity and later washout of HCC, with reported inherent superior sensitivity to microbubbles compared to the sensitivity of CT or MRI to iodinated or gadolinium-based agents (Fig. 2) [30]. Furthermore, the real-time nature of CEUS imaging allows the demonstration of enhancement, whereas CT/MRI may fail to show enhancement because of inappropriate arterial-phase timing (Fig. 3) [31]. Not surprisingly, the sensitivity of CEUS in the detection of arterial hypervascularity from nodules in liver cirrhosis has been reported to be significantly higher than that of CT/MRI [32-34].

Interestingly enough, the enhancement patterns of HCC on CEUS are related to its pathology. In a study by Jang and colleagues on 112 HCCs, hypervascularity was more frequently seen in moderately differentiated HCCS than in well or poorly differentiated HCCs [35]. Hence, the imaging findings on CEUS may overlap between DNs and well-differentiated HCCs due to the variable blood supply (Fig. 4) [28].

Furthermore, washout time was reported to be significantly shorter in moderately and poorly differentiated HCCs than in welldifferentiated tumors [35]. This finding is of clinical relevance considering that washout in HCC tends to be late and often begins later than 90 seconds after injection, whereas metastases or intrahepatic cholangiocarcinomas usually show arterial-phase hypervascularity followed by show rapid washout ( $<60$ seconds) (Fig. 5) [36]. Hence, when performing CEUS, a long observation period (up to $\sim 5$ minutes, or as long as enhancement lasts) is essential to avoid missing the late (>1 minute), weak washout typical of HCC (Fig. 2).

Furthermore, size may be a factor influencing arterial contrastenhancement patterns: in a study by Tada et al. [37], 63 of 68 $(92.6 \%)$ small HCCs ( $<3 \mathrm{~cm}$ in size) showed a mainly diffuse homogeneous arterial-phase enhancement pattern, and 66 of 68 (97\%) small HCCs showed regular tumor margins on CEUS. In large HCCS, a heterogeneous arterial-phase enhancement pattern can often be observed due to non-enhancing areas related to fibrosis, necrosis, or internal hemorrhage (Fig. 6).

\section{Wash-in Issues: Differentiating HCC from Other Arterial- Enhancing Lesions}

It is well documented that up to $93 \%$ of small hypervascular foci seen on CT/MRI in the arterial phase only represent non-neoplastic 


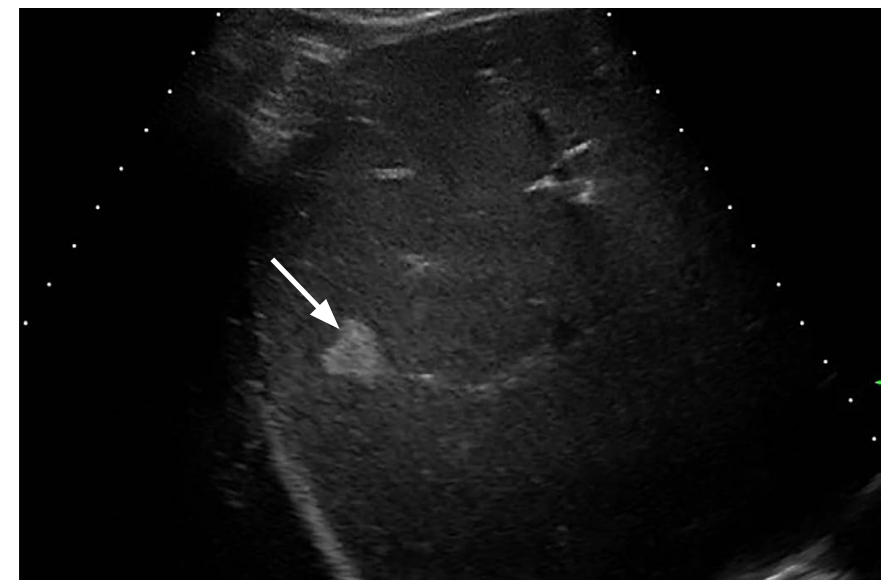

A

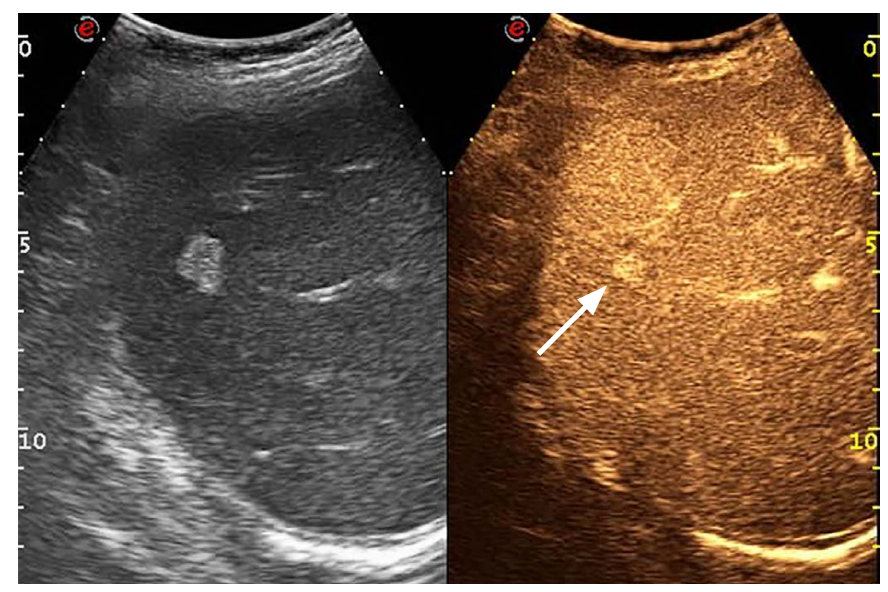

C

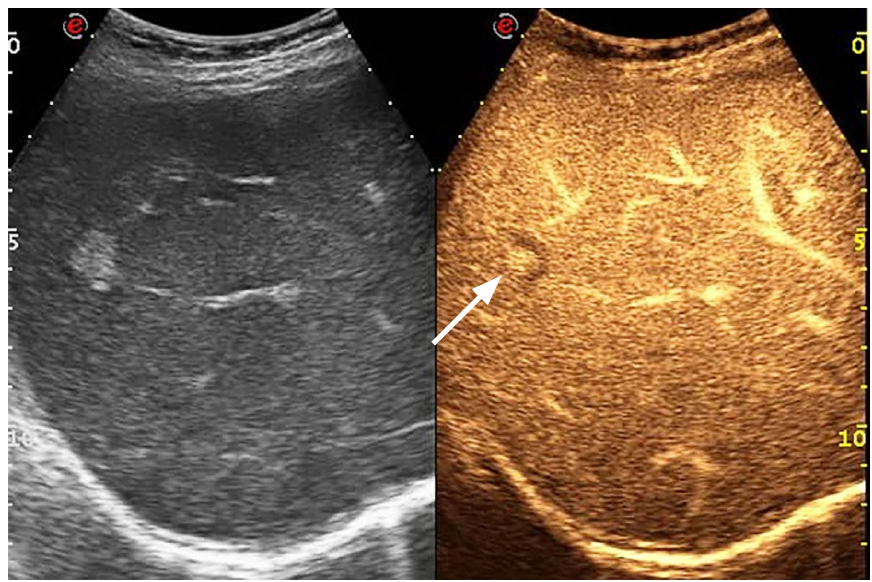

B

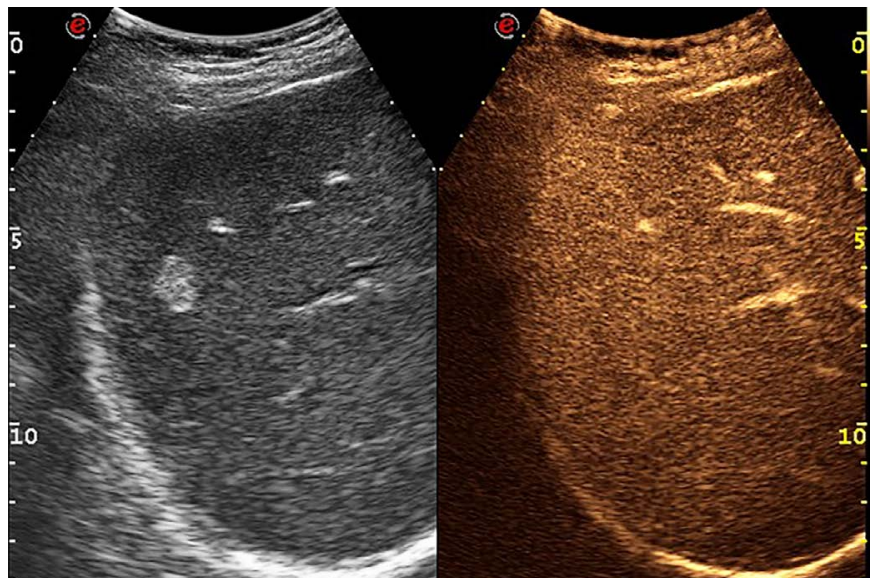

D

Fig. 7. Liver hemangioma in a 48-year-old woman with hepatitis C-related cirrhosis.

A. Baseline image shows a homogeneously hyperechoic lesion measuring $1.7 \mathrm{~cm}$ in the seventh hepatic segment (arrow). B. In the arterial phase, peripheral globular enhancement is evident (arrow); C, D. The lesion presents progressive centripetal fill-in in the extended portalvenous phase (arrow), complete 3 minutes after the start of the sulfur hexafluoride injection.

pseudolesions, especially arterioportal shunts, even in patients with pathologically proven HCC $[38,39]$.

Furthermore, thanks to its high temporal resolution and realtime nature, CEUS is able to overcome the fugacity of the arterial phase, allowing a precise assessment of early vascular filling patterns, often crucial for differentiating small, rapidly enhancing, benign hypervascular lesions from well-differentiated HCC not showing washout. Hence, CEUS can easily characterize flash-filling hemangiomas and focal nodular hyperplasia by demonstrating early peripheral nodular enhancement, followed by centripetal fill-in and a spoke-wheel pattern with centrifugal progression, respectively (Fig. 7) [40-44].

Additionally, small cholangiocarcinomas usually show arterial phase enhancement on CEUS, with either a rim-like or diffuse pattern, the latter of which can be homogeneous or heterogeneous, followed by rapid washout (Fig. 5) [45-47]. Usually, MRI should be performed when these unusual enhancement patterns for HCC are observed on CEUS, and eventually biopsy sampling whenever necessary.

CEUS-specific image processing techniques, such as real-time maximum intensity processing, may further clarify arterial-phase contrast-enhancement patterns, thus improving the characterization of liver nodules [48].

\section{Washout Issues: Differentiating HCC from Other Washing- out Lesions}

The extracellular contrast agents used with CT or MRI can progressively leak into the tumor interstitium, whereas the microbubbles in CEUS are purely intravascular. This characteristic explains why, regardless of the arterial contrast-enhancement 
pattern, all types of malignant liver lesions show washout on CEUS, whereas CT or MRI may not show washout in malignant tumors with high vascular permeability and large extracellular interstitial space (Fig. 5). The main implication of this feature is that, in patients with cirrhosis, the observation of washout is only suggestive of malignancy, but not sufficient to differentiate HCC from nonHCC malignancies. For this purpose, a careful characterization of the timing and degree of washout may allow a correct diagnosis. Early (i.e., $<60$ seconds) and marked or punched-out washout is characteristic of non-HCC lesions, whereas late ( $>60$ seconds) and mild washout is characteristic of HCC lesions, such as intrahepatic cholangiocarcinoma (ICC) or metastases [49-51]. On the other hand, early but mild washout or late but marked washout are suggestive of malignancy in general and not specific of any particular malignancy. These lesions should be further investigated by means of MRI or biopsy [52].

\section{HCC: CEUS in Clinical Practice}

Despite its inherent advantages, the American Association for the Study of Liver Diseases (AASLD) and European Association for the Study of the Liver (EASL)/European Organization for Research and Treatment of Cancer guidelines on HCC updated in 2011 and 2012, respectively, did not include the use of CEUS in the diagnostic imaging workup, mainly due to the lack of reported specificity in the differentiation between HCC and ICC, the latter of which occurs at a rate of $2 \%-5 \%$ of all new nodules in cirrhosis $[47,53]$. Nevertheless, the above-discussed differences in arterial contrast enhancement and in the timing and degree of washout occurring in ICC lesions has enabled to it to be better differentiated from HCC. The former often shows rim-like arterial contrast enhancement followed by early (i.e., $<60$ seconds) and marked washout, whereas the latter usually shows non-rim-like arterial contrast enhancement followed by late (i.e., $>60$ seconds) and mild washout $[45,50,54-57]$. This refinement in CEUS capability in the characterization of ICC has led various scientific societies, including Italian, German and British

\section{$\varnothing$ CEUS LI-RADS ${ }^{\circledR}$ V2017 CORE}

(For CEUS with Pure Blood Pool Agents)

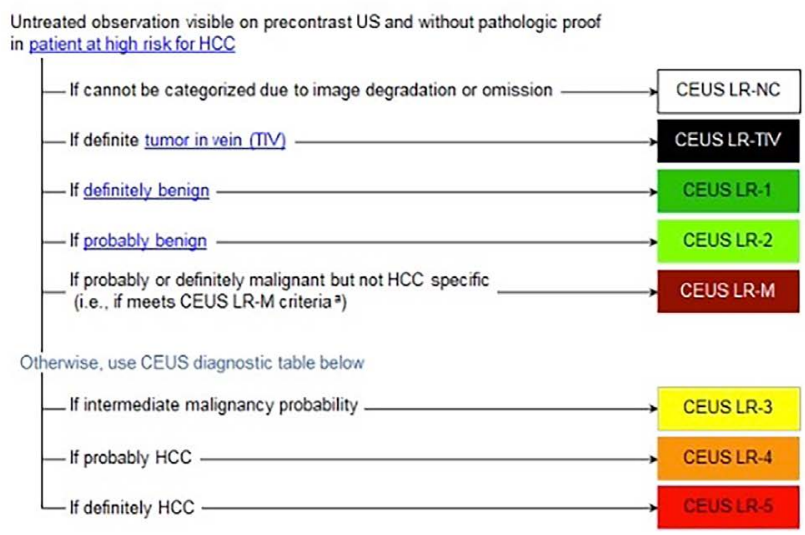

CEUS Diagnostic Table

\begin{tabular}{|c|c|c|c|c|}
\hline \multirow{2}{*}{$\begin{array}{l}\begin{array}{l}\text { Arterial phase } \\
\text { hyperenhancement (APHE) }\end{array} \\
\text { Nodule size }(\mathrm{mm})\end{array}$} & \multicolumn{2}{|c|}{ No APHE } & \multicolumn{2}{|c|}{$\begin{array}{c}\text { APHE } \\
\text { (not rim }{ }^{\circ} \text {, not peripheral } \\
\text { discontinuous globular }^{\circ} \text { ) }\end{array}$} \\
\hline & $<20$ & 220 & $<10$ & 210 \\
\hline No washout of any type & CEUS LR-3 & CEUSLR-3 & CEUS LR-3 & CEUS LR-4 \\
\hline Late and mild washout & CEUSLR-3 & CEUSLR-4 & CEUS LR-4 & CEUSLR-6 \\
\hline \multicolumn{2}{|c|}{ a. CEUS LR-M criteria - any of following: } & $\begin{array}{l}\operatorname{rim} \text { APHE OR } \\
\text { early }(<60 \text { s) w } \\
\text { marked washo }\end{array}$ & out $O R$ & \\
\hline \multicolumn{5}{|c|}{$\begin{array}{l}\text { b. rim APHE indicates CEUS LR-M } \\
\text { c. peripheral discontinuous globular indicates hemangioma (CEUS LR-1) }\end{array}$} \\
\hline
\end{tabular}

Fig. 8. Contrast Enhanced Ultrasound Liver Imaging Reporting and Data System (CEUS LI-RADS) algorithm. CEUS Li-RADS v2017 Core (2017) with permission of American College of Radiology [59].

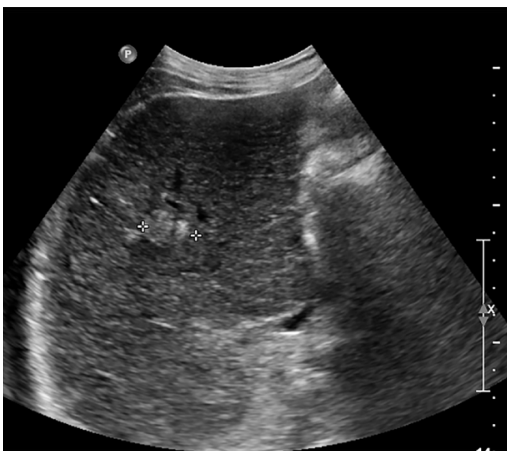

A

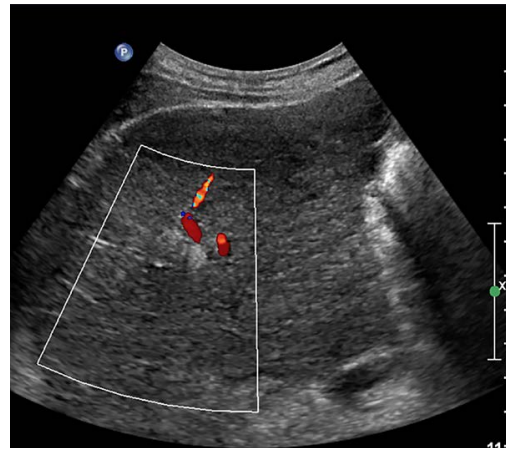

B

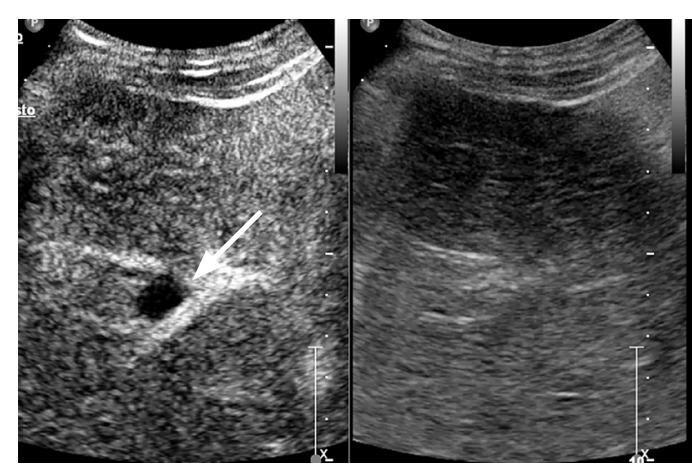

C

Fig. 9. Complete response after radiofrequency ablation of hepatocellular carcinoma in a 58-year-old woman.

A, B. An oblique ascending right subcostal baseline ultrasound image shows a 1.4-cm-sized inhomogeneous, mainly hyperechoic area in the sixth segment (calipers) (A) with no vascular signal on color Doppler (B). C. On contrast-enhanced ultrasonography in the arterial phase (30 seconds after sulfur hexafluoride injection), the lesion shows a lack of contrast enhancement (arrow). 
societies, to suggest the use of CEUS in the diagnostic algorithm of HCC in their guidelines (http://www.webaisf.org, http://www.drg. de, and http://www.nice.org.uk, respectively). In the latest version of EASL guidelines on the management of HCC, CEUS is considered a diagnostic tool for HCC, as well as CT and MRI [58].

The American College of Radiology (ACR) has also endorsed the use of CEUS in the diagnostic work-up of HCC. The ACR released in 2016, and then updated in 2017, a dedicated freely-available Contrast Enhanced Ultrasound Liver Imaging Reporting and Data System (CEUS LI-RADS) which uses the size of a lesion, the type and degree of arterial phase enhancement, the presence of washout, and the timing and degree of washout as the major features for categorization of FLLs in patients at high risk for HCC development (Fig. 8) [59]. CEUS LI-RADS is expected to improve the role of CEUS as a major imaging tool, as well as CT and MRI, and facilitate its incorporation into a multimodality imaging approach for liver studies in patients at risk for HCC [60]. The CEUS LI-RADS algorithm has been reported to be highly specific for HCC, while at the same time avoiding the misdiagnosis of ICC [61]. In particular, a study reported that CEUS showed high specificity (92.9\%), but limited sensitivity $(39.6 \%)$, in the diagnosis of HCC, thus suggesting that CEUS may play a role both in the characterization of nodules detected

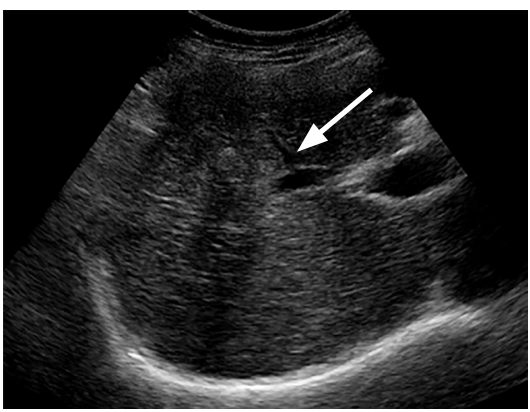

A

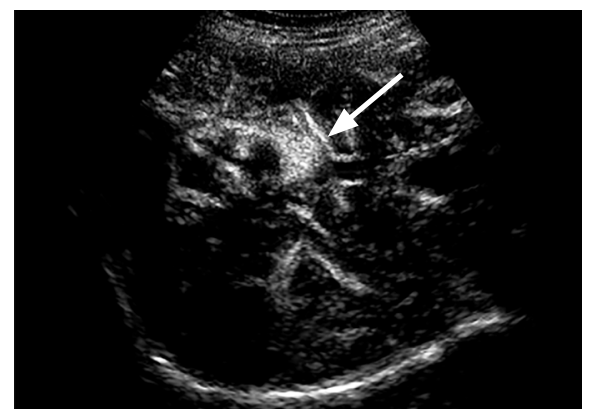

B
Fig. 10. Residual tumor after radiofrequency ablation of hepatocellular carcinoma.

A. An axial baseline image in a 54-yearold woman shows a $1.6-\mathrm{cm}$-sized slightly hyperechoic area in the fifth segment (arrow). B. Contrast-enhanced ultrasonography in the arterial phase (17 seconds after sulfur hexafluoride injection) shows a clear-cut area of eccentrically located hypervascular tissue around the treated area (arrow). C. Threedimensional i-Slice reconstruction better depicts the same finding in each slice (arrows).

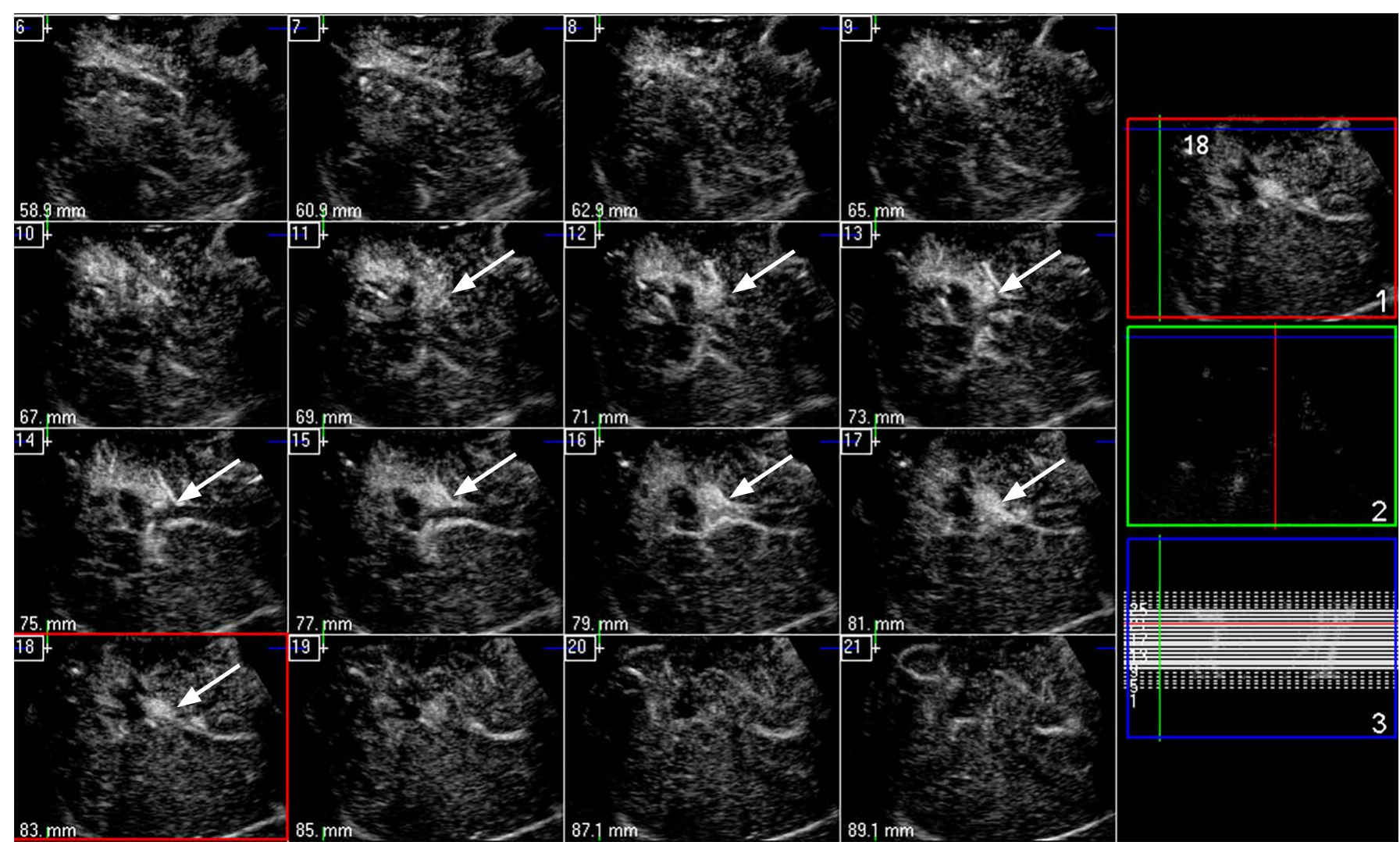

C 


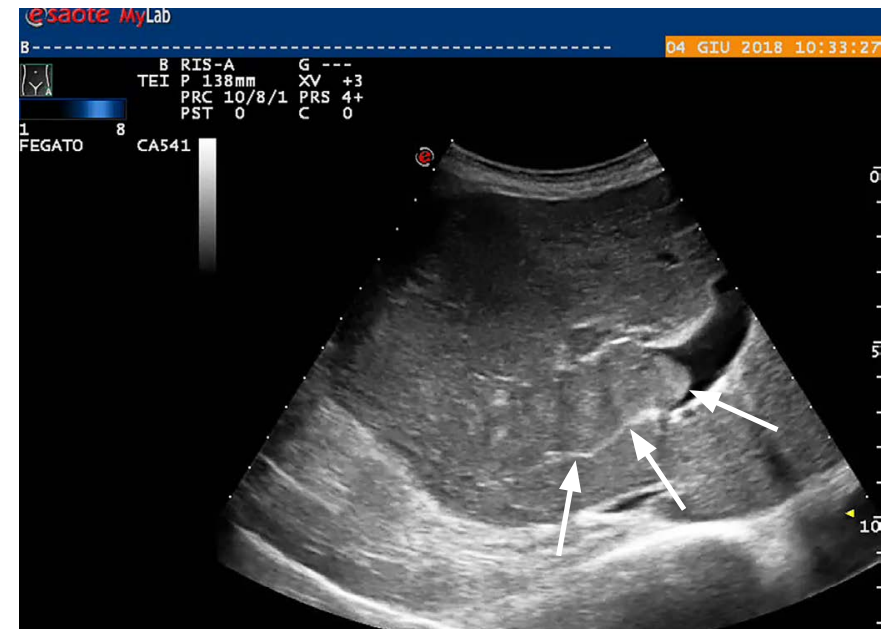

A

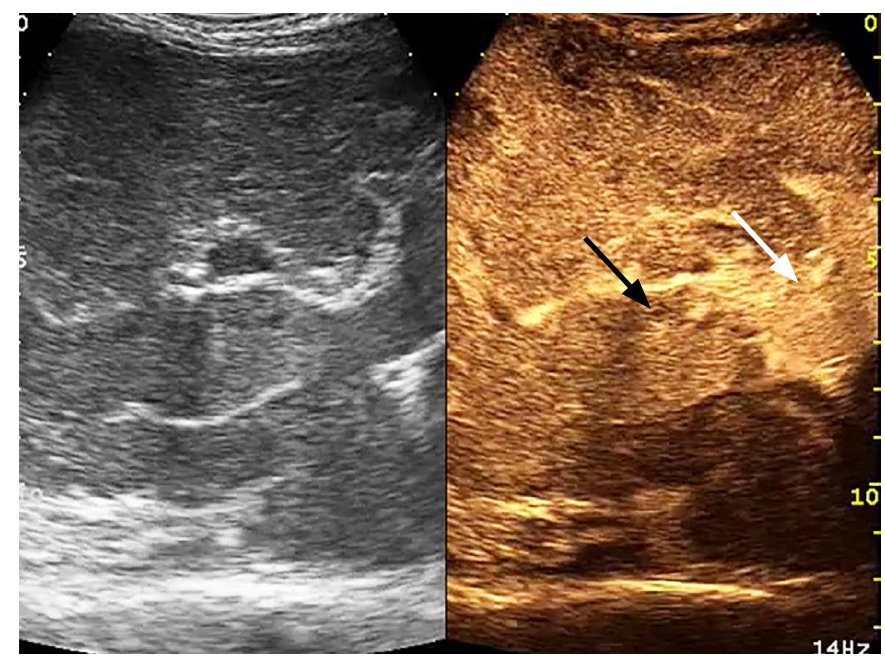

C

during surveillance and in a sequential combined approach after indeterminate CT or MRI studies [62].

\section{HCC: CEUS in the Assessment of Therapeutic Response}

Over the past decade, locoregional therapies (LRTs) have emerged as a valid alternative to conventional surgery in patients with HCC $[63,64]$. LRTs are usually delivered under US guidance, but correct targeting of the tumor may be inaccurate or even impossible for small HCC nodules, which are poorly defined on US. In this setting, CEUS may facilitate radiofrequency ablation (RFA) electrode placement in hypervascular HCC, which is poorly depicted by B-mode US $[65,66]$.

Newly developed techniques, such as fusion imaging between US and CT/MRI datasets, can further improve the conspicuity of HCCs and the feasibility of percutaneous RFA of HCCs not visible on conventional US, including even subcentimeter HCCs, thus increasing

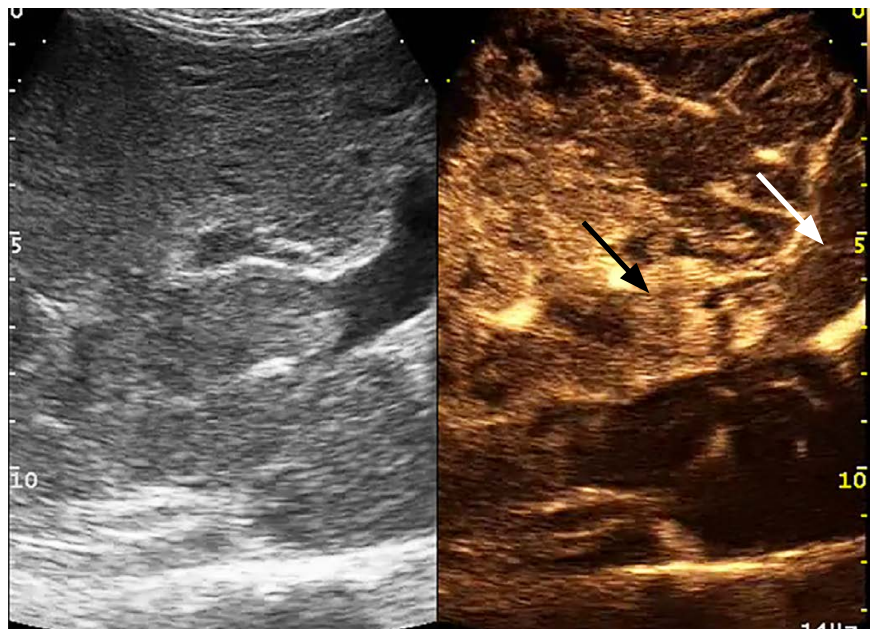

B

Fig. 11. Malignant portal thrombus in a 83-year-old man with hepatitis B-related liver cirrhosis.

A. An oblique ascending right subcostal baseline ultrasound image shows the lumen of the right branch of the portal vein filled with thrombus isoechoic to the adjacent liver parenchyma (arrows). B. On contrast-enhanced ultrasonography in the arterial phase (15 seconds after sulfur hexafluoride injection) the thrombus shows evident contrast enhancement (black arrow), whereas the left portal branch is still anechoic (white arrow). C. At 122 seconds after the injection, the thrombus shows mild washout (black arrow), whereas the left portal branch is normally perfused (white arrow).

the success rate of percutaneous ablation therapy for HCC [6769]. Furthermore, an accurate assessment of therapeutic response is of crucial importance, considering that complete tumor ablation significantly increases the likelihood of patient survival, whereas the presence of residual unablated tumor calls for additional treatment $[70,71]$. Similarly, CEUS suggests that a procedure has been successful when a previously enhancing, hypervascularized HCC nodule shows a lack of contrast enhancement after treatment, whereas still viable tumoral tissue is typically depicted as an arterialenhancing focus with portal-venous washout (Fig. 9) [72,73]. More recently, 3-dimensional CEUS has been reported to improve the study of tumor vascularity, thereby enabling the response to RFA to be evaluated in the three orthogonal planes (Fig. 10) $[74,75]$.

\section{CEUS: Portal Vein Thrombosis Assessment}

Abnormal venous drainage evolves during hepatocarcinogenesis 
from the hepatic veins to portal vessels, explaining the predilection of HCC to invade into and disseminate via the portal vein, instead of the hepatic veins [27]. The detection of malignant portal or hepatic vein thrombosis is crucial for proper clinical management. However, benign thrombosis can be found, even without malignant disease, in $4.5 \%-26 \%$ of patients with chronic liver disease [76]. Raza et al. [77] reported that CEUS was able to differentiate malignant and benign venous thrombosis associated with HCC with high diagnostic accuracy, by showing arterial enhancement of the malignant thrombus (Fig. 11).

\section{CEUS: Limitations}

CEUS shares many limitations with conventional US. Large body habitus, intervening bowel gas, a poor acoustic window, movement artifacts, or even poor clinical conditions may prevent obtaining an optimal CEUS scan. Furthermore, tiny lesions deeply located in the liver parenchyma may be difficult to explore with CEUS, especially at a depth more than $12 \mathrm{~cm}$ and in livers with diffuse fibro-fatty changes [78].

Multiple injections of contrast agent are required to investigate different lesions in the same liver and, sometimes, to properly evaluate even a single lesion. Overlapping findings between malignant and benign lesions may exist. In those patients, other imaging modalities, such as multidetector CT or MRI, should be performed for staging or characterization purposes.

Adequate training and knowledge is required to perform an optimal CEUS study; consequently, teaching issues should be considered in order to achieve a reasonable and widespread diagnostic quality. Intravenous administration of a contrast agent must be performed under medical control, which requires additional time, as does the off-line visualization of multiple video clips for the accurate evaluation of all phases of contrast enhancement, affecting the throughput of already busy US departments.

\section{HCC and CEUS: Final Considerations}

Almost 20 years after its commercial introduction, CEUS is increasingly being recognized as a safe and robust imaging modality, which enables real-time, adequate depictions of the contrast-enhancement patterns of FLLS, including HCC. This unique feature of CEUS has dramatically improved the accuracy of US in the detection and characterization of HCC, as well as in the guidance and evaluation of response to therapeutic procedures [79-81].

Currently, CEUS is increasingly being performed on a routine basis and, in the appropriate clinical setting, is included as a part of the suggested diagnostic work-up of HCC, resulting in better patient management and cost-effective delivery of therapy $[82,83]$.
ORCID: Tommaso Vincenzo Bartolotta: https://orcid.org/0000-0002-8808-379X; Adele Taibbi: https://orcid.org/0000-0001-6442-744X; Massimo Midiri: https://orcid.org/00000003-1824-7549; Roberto Lagalla: https://orcid.org/0000-0003-2140-7603

\section{Author Contributions}

Conceptualization: Bartolotta TV. Drafting of the manuscript: Bartolotta TV. Critical revision of the manuscript: all authors. Approval of the final version of the manuscript: all authors

\section{Conflict of Interest}

No potential conflict of interest relevant to this article was reported.

\section{References}

1. International Agency for Research on Cancer. Liver [Internet]. Lyon: The Global Cancer Observatory, 2018 [cited 2019 Jan 8]. Available from: http://gco.iarc.fr/today/data/factsheets/cancers/11-Liver-factsheet.pdf.

2. Dimitroulis D, Damaskos C, Valsami S, Davakis S, Garmpis N, Spartalis $\mathrm{E}$, et al. From diagnosis to treatment of hepatocellular carcinoma: an epidemic problem for both developed and developing world. World J Gastroenterol 2017;23:5282-5294.

3. Heimbach JK, Kulik LM, Finn RS, Sirlin CB, Abecassis MM, Roberts $L R$, et al. AASLD guidelines for the treatment of hepatocellular carcinoma. Hepatology 2018;67:358-380.

4. Omata M, Cheng AL, Kokudo N, Kudo M, Lee JM, Jia J, et al. Asia-Pacific clinical practice guidelines on the management of hepatocellular carcinoma: a 2017 update. Hepatol Int 2017;11:317-370.

5. Elsayes KM, Hooker JC, Agrons MM, Kielar AZ, Tang A, Fowler KJ, et al. 2017 version of LI-RADS for CT and MR imaging: an update. Radiographics 2017;37:1994-2017.

6. Marrero JA, Ahn J, Rajender Reddy K; Americal College of Gastroenterology. ACG clinical guideline: the diagnosis and management of focal liver lesions. Am J Gastroenterol 2014;109:1328-1347.

7. Kudo $M$, Matsui 0 , Izumi $N$, lijima $H$, Kadoya $M$, Imai $Y$, et al. JSH consensus-based clinical practice guidelines for the management of hepatocellular carcinoma: 2014 update by the Liver Cancer Study Group of Japan. Liver Cancer 2014;3:458-468.

8. Korean Liver Cancer Study Group (KLCSG); National Cancer Center, Korea (NCC). 2014 Korean Liver Cancer Study Group-National Cancer Center Korea practice guideline for the management of hepatocellular carcinoma. Korean J Radiol 2015;16:465-522.

9. Korean Society of Abdominal Radiology. Diagnosis of hepatocellular carcinoma with gadoxetic acid-enhanced MRI: 2016 consensus recommendations of the Korean Society of Abdominal Radiology. Korean J Radiol 2017;18:427-443.

10. Bruix J, Sherman M; American Association for the Study of Liver 
Diseases. Management of hepatocellular carcinoma: an update. Hepatology 2011;53:1020-1022.

11. European Association for Study of Liver; European Organisation for Research and Treatment of Cancer. EASL-EORTC clinical practice guidelines: management of hepatocellular carcinoma. Eur J Cancer 2012;48:599-641.

12. Kumar A, Acharya SK, Singh SP, Saraswat VA, Arora A, Duseja $A$, et al. The Indian National Association for Study of the Liver (INASL) consensus on prevention, diagnosis and management of hepatocellular carcinoma in India: the Puri Recommendations. J Clin Exp Hepatol 2014;4(Suppl 3):S3-S26.

13. Thomsen HS. Nephrogenic systemic fibrosis: history and epidemiology. Radiol Clin North Am 2009;47:827-831.

14. Tao SM, Wichmann JL, Schoepf UJ, Fuller SR, Lu GM, Zhang LJ. Contrast-induced nephropathy in CT: incidence, risk factors and strategies for prevention. Eur Radiol 2016;26:3310-3318.

15. Bartolotta TV, Taibbi A, Midiri M, Lagalla R. Focal liver lesions: contrast-enhanced ultrasound. Abdom Imaging 2009;34:193-209.

16. Giambelluca D, Taibbi A, Midiri M, Bartolotta TV. The "spoke wheel" sign in hepatic focal nodular hyperplasia. Abdom Radiol (NY) 2019;44:1183-1184.

17. Bartolotta TV, Taibbi A, Midiri M, La Grutta L, De Maria M, Lagalla R. Characterisation of focal liver lesions undetermined at grey-scale US: contrast-enhanced US versus 64-row MDCT and MRI with liverspecific contrast agent. Radiol Med 2010;115:714-731.

18. Bartolotta TV, Taibbi A, Midiri M, Matranga D, Solbiati L, Lagalla R. Indeterminate focal liver lesions incidentally discovered at grayscale US: role of contrast-enhanced sonography. Invest Radiol 2011;46:106-115.

19. Bartolotta TV, Vernuccio F, Taibbi A, Lagalla R. Contrast-enhanced ultrasound in focal liver lesions: where do we stand? Semin Ultrasound CT MR 2016;37:573-586.

20. Jo PC, Jang HJ, Burns PN, Burak KW, Kim TK, Wilson SR. Integration of contrast-enhanced US into a multimodality approach to imaging of nodules in a cirrhotic liver: how I do it. Radiology 2017;282:317331.

21. Wu M, Li L, Wang J, Zhang Y, Guo Q, Li X, et al. Contrast-enhanced US for characterization of focal liver lesions: a comprehensive meta-analysis. Eur Radiol 2018;28:2077-2088.

22. Quaia E. Microbubble ultrasound contrast agents: an update. Eur Radiol 2007; 17:1995-2008.

23. Piscaglia F, Bolondi L; Italian Society for Ultrasound in Medicine and Biology (SIUMB) Study Group on Ultrasound Contrast Agents. The safety of Sonovue in abdominal applications: retrospective analysis of 23188 investigations. Ultrasound Med Biol 2006;32:1369-1375.

24. Harvey CJ, Alsafi A, Kuzmich S, Ngo A, Papadopoulou I, Lakhani $A$, et al. Role of US contrast agents in the assessment of indeterminate solid and cystic lesions in native and transplant kidneys. Radiographics 2015;35:1419-1430.
25. Claudon M, Dietrich CF, Choi BI, Cosgrove DO, Kudo M, Nolsoe CP, et al. Guidelines and good clinical practice recommendations for contrast enhanced ultrasound (CEUS) in the liver - update 2012: a WFUMB-EFSUMB initiative in cooperation with representatives of AFSUMB, AIUM, ASUM, FLAUS and ICUS. Ultrasound Med Biol 2013;39:187-210.

26. Matsui O, Kadoya M, Kameyama T, Yoshikawa J, Takashima T, Nakanuma Y, et al. Benign and malignant nodules in cirrhotic livers: distinction based on blood supply. Radiology 1991;178:493-497.

27. Choi JY, Lee JM, Sirlin CB. CT and MR imaging diagnosis and staging of hepatocellular carcinoma: part I. Development, growth, and spread: key pathologic and imaging aspects. Radiology 2014;272:635-654.

28. Kim TK, Lee KH, Khalili K, Jang HJ. Hepatocellular nodules in liver cirrhosis: contrast-enhanced ultrasound. Abdom Imaging 2011;36:244-263.

29. Roberts LR, Sirlin CB, Zaiem F, Almasri J, Prokop LJ, Heimbach JK, et al. Imaging for the diagnosis of hepatocellular carcinoma: a systematic review and meta-analysis. Hepatology 2018;67:401421.

30. Rossi S, Ghittoni G, Ravetta V, Torello Viera F, Rosa L, Serassi M, et al. Contrast-enhanced ultrasonography and spiral computed tomography in the detection and characterization of portal vein thrombosis complicating hepatocellular carcinoma. Eur Radiol 2008; 18:1749-1756.

31. Wilson SR, Kim TK, Jang HJ, Burns PN. Enhancement patterns of focal liver masses: discordance between contrast-enhanced sonography and contrast-enhanced CT and MRI. AJR Am J Roentgenol 2007;189:W7-W12.

32. Maruyama H, Takahashi M, Ishibashi H, Yoshikawa M, Yokosuka 0 . Contrast-enhanced ultrasound for characterisation of hepatic lesions appearing non-hypervascular on $\mathrm{CT}$ in chronic liver diseases. Br J Radiol 2012;85:351-357.

33. Takahashi M, Maruyama $H$, Shimada $T$, Kamezaki $H$, Sekimoto $T$, Kanai $F$, et al. Characterization of hepatic lesions $(</=30 \mathrm{~mm})$ with liver-specific contrast agents: a comparison between ultrasound and magnetic resonance imaging. Eur J Radiol 2013;82:75-84.

34. Sugimoto K, Moriyasu F, Shiraishi J, Saito K, Taira J, Saguchi T, et al. Assessment of arterial hypervascularity of hepatocellular carcinoma: comparison of contrast-enhanced US and gadoxetate disodiumenhanced MR imaging. Eur Radiol 2012;22:1205-1213.

35. Jang HJ, Kim TK, Burns PN, Wilson SR. Enhancement patterns of hepatocellular carcinoma at contrast-enhanced US: comparison with histologic differentiation. Radiology 2007;244:898-906.

36. Bhayana D, Kim TK, Jang HJ, Burns PN, Wilson SR. Hypervascular liver masses on contrast-enhanced ultrasound: the importance of washout. AJR Am J Roentgenol 2010;194:977-983.

37. Tada T, Kumada T, Toyoda H, Ito T, Sone $Y$, Kaneoka $Y$, et al. Utility of contrast-enhanced ultrasound with perflubutane for diagnosing the 
macroscopic type of small nodular hepatocellular carcinomas. Eur Radiol 2014;24:2157-2166.

38. Kim TK, Choi BI, Han JK, Chung JW, Park JH, Han MC. Nontumorous arterioportal shunt mimicking hypervascular tumor in cirrhotic liver: two-phase spiral CT findings. Radiology 1998;208:597-603.

39. Holland AE, Hecht EM, Hahn WY, Kim DC, Babb JS, Lee VS, et al. Importance of small $(<$ or $=20-\mathrm{mm}$ ) enhancing lesions seen only during the hepatic arterial phase at MR imaging of the cirrhotic liver: evaluation and comparison with whole explanted liver. Radiology 2005;237:938-944.

40. Bartolotta TV, Taibbi A, Matranga D, Malizia G, Lagalla R, Midiri M. Hepatic focal nodular hyperplasia: contrast-enhanced ultrasound findings with emphasis on lesion size, depth and liver echogenicity. Eur Radiol 2010;20:2248-2256.

41. Bartolotta TV, Midiri M, Quaia E, Bertolotto M, Galia M, Cademartiri $F$, et al. Liver haemangiomas undetermined at grey-scale ultrasound: contrast-enhancement patterns with SonoVue and pulse-inversion US. Eur Radiol 2005;15:685-693.

42. Bartolotta TV, Midiri M, Scialpi M, Sciarrino E, Galia M, Lagalla R. Focal nodular hyperplasia in normal and fatty liver: a qualitative and quantitative evaluation with contrast-enhanced ultrasound. Eur Radiol 2004;14:583-591.

43. Bartolotta TV, Midiri M, Galia M, lovane A, Runza G, Carcione A, et al. Atypical liver hemangiomas: contrast-enhancement patterns with SH U 508A and pulse-inversion US. Radiol Med 2003;106:320328.

44. Bartolotta TV, Midiri M, Quaia E, Bertolotto M, Galia M, Cademartiri $F$, et al. Benign focal liver lesions: spectrum of findings on SonoVue-enhanced pulse-inversion ultrasonography. Eur Radiol 2005;15:1643-1649.

45. Wildner D, Bernatik T, Greis C, Seitz K, Neurath MF, Strobel D. CEUS in hepatocellular carcinoma and intrahepatic cholangiocellular carcinoma in 320 patients: early or late washout matters: a subanalysis of the DEGUM multicenter trial. Ultraschall Med 2015;36:132-139.

46. Chen LD, Ruan SM, Liang JY, Yang Z, Shen SL, Huang Y, et al. Differentiation of intrahepatic cholangiocarcinoma from hepatocellular carcinoma in high-risk patients: a predictive model using contrast-enhanced ultrasound. World J Gastroenterol 2018;24:3786-3798.

47. Vilana R, Forner A, Bianchi L, Garcia-Criado A, Rimola J, de Lope $C R$, et al. Intrahepatic peripheral cholangiocarcinoma in cirrhosis patients may display a vascular pattern similar to hepatocellular carcinoma on contrast-enhanced ultrasound. Hepatology 2010;51:2020-2029.

48. Wilson SR, Jang HJ, Kim TK, lijima H, Kamiyama N, Burns PN. Realtime temporal maximum-intensity-projection imaging of hepatic lesions with contrast-enhanced sonography. AJR Am J Roentgenol 2008; 190:691-695.
49. Han J, Liu Y, Han F, Li Q, Yan C, Zheng W, et al. The degree of contrast washout on contrast-enhanced ultrasound in distinguishing intrahepatic cholangiocarcinoma from hepatocellular carcinoma. Ultrasound Med Biol 2015;41:3088-3095.

50. de Sio I, Iadevaia MD, Vitale LM, Niosi M, Del Prete A, de Sio $C$, et al. Optimized contrast-enhanced ultrasonography for characterization of focal liver lesions in cirrhosis: a single-center retrospective study. United European Gastroenterol J 2014;2:279287.

51. Li R, Yuan MX, Ma KS, Li XW, Tang CL, Zhang XH, et al. Detailed analysis of temporal features on contrast enhanced ultrasound may help differentiate intrahepatic cholangiocarcinoma from hepatocellular carcinoma in cirrhosis. PLoS One 2014;9:e98612.

52. Jang HJ, Kim TK, Burns PN, Wilson SR. CEUS: An essential component in a multimodality approach to small nodules in patients at high-risk for hepatocellular carcinoma. Eur J Radiol 2015;84:1623-1635.

53. Galassi M, lavarone M, Rossi S, Bota S, Vavassori S, Rosa L, et al. Patterns of appearance and risk of misdiagnosis of intrahepatic cholangiocarcinoma in cirrhosis at contrast enhanced ultrasound. Liver Int 2013;33:771-779.

54. Li R, Zhang X, Ma KS, Li XW, Xia F, Zhong H, et al. Dynamic enhancing vascular pattern of intrahepatic peripheral cholangiocarcinoma on contrast-enhanced ultrasound: the influence of chronic hepatitis and cirrhosis. Abdom Imaging 2013;38:112119.

55. Yuan MX, Li R, Zhang XH, Tang CL, Guo YL, Guo DY, et al. Factors affecting the enhancement patterns of intrahepatic cholangiocarcinoma (ICC) on contrast-enhanced ultrasound (CEUS) and their pathological correlations in patients with a single lesion. Ultraschall Med 2016;37:609-618.

56. Liu GJ, Wang W, Lu MD, Xie XY, Xu HX, Xu ZF, et al. Contrastenhanced ultrasound for the characterization of hepatocellular carcinoma and intrahepatic cholangiocarcinoma. Liver Cancer 2015;4:241-252.

57. Wildner D, Pfeifer L, Goertz RS, Bernatik T, Sturm J, Neurath MF, et al. Dynamic contrast-enhanced ultrasound (DCE-US) for the characterization of hepatocellular carcinoma and cholangiocellular carcinoma. Ultraschall Med 2014;35:522-527.

58. European Association for the Study of the Liver. EASL Clinical Practice Guidelines: Management of hepatocellular carcinoma. J Hepatol 2018;69:182-236.

59. CEUS Li-RADS v2017 Core [Internet]. Reston, VA: American College of Radiology, 2017 [cited 2018 Oct 18]. Available from: https:// www.acr.org/-/media/ACR/Images/Clinical-Resources/RADS/LI RADS/CEUSv2017Core.png.

60. Wilson SR, Lyshchik A, Piscaglia F, Cosgrove D, Jang HJ, Sirlin C, et al. CEUS LI-RADS: algorithm, implementation, and key differences from CT/MRI. Abdom Radiol (NY) 2018;43:127-142. 
61. Terzi E, lavarone M, Pompili M, Veronese L, Cabibbo G, Fraquelli M, et al. Contrast ultrasound LI-RADS LR-5 identifies hepatocellular carcinoma in cirrhosis in a multicenter restropective study of 1,006 nodules. J Hepatol 2018;68:485-492.

62. Aube C, Oberti F, Lonjon J, Pageaux G, Seror O, N'Kontchou G, et al. EASL and AASLD recommendations for the diagnosis of HCC to the test of daily practice. Liver Int 2017;37:1515-1525.

63. Dodd GD 3rd, Soulen MC, Kane RA, Livraghi T, Lees WR, Yamashita Y, et al. Minimally invasive treatment of malignant hepatic tumors: at the threshold of a major breakthrough. Radiographics 2000;20:927.

64. Taibbi A, Furlan A, Sandonato L, Bova V, Galia M, Marin D, et al. Imaging findings of liver resection using a bipolar radiofrequency electrosurgical device: initial observations. Eur J Radiol 2012;81:663-670.

65. Minami Y, Kudo M. Review of dynamic contrast-enhanced ultrasound guidance in ablation therapy for hepatocellular carcinoma. World J Gastroenterol 2011;17:4952-4959.

66. Kim AY, Lee MW, Rhim H, Cha DI, Choi D, Kim YS, et al. Pretreatment evaluation with contrast-enhanced ultrasonography for percutaneous radiofrequency ablation of hepatocellular carcinomas with poor conspicuity on conventional ultrasonography. Korean J Radiol 2013;14:754-763.

67. Lee MW, Rhim H, Cha DI, Kim YJ, Choi D, Kim YS, et al. Percutaneous radiofrequency ablation of hepatocellular carcinoma: fusion imaging guidance for management of lesions with poor conspicuity at conventional sonography. AJR Am J Roentgenol 2012;198:1438-1444.

68. Ahn SJ, Lee JM, Lee DH, Lee SM, Yoon JH, Kim YJ, et al. Real-time US-CT/MR fusion imaging for percutaneous radiofrequency ablation of hepatocellular carcinoma. J Hepatol 2017;66:347-354.

69. Song KD, Lee MW, Rhim H, Kang TW, Cha DI, Sinn DH, et al. Percutaneous US/MRI fusion-guided radiofrequency ablation for recurrent subcentimeter hepatocellular carcinoma: technical feasibility and therapeutic outcomes. Radiology 2018;288:878886.

70. Bartolotta TV, Taibbi A, Matranga D, Sandonato L, Asta S, Midiri $M$, et al. Incidence of new foci of hepatocellular carcinoma after radiofrequency ablation: role of multidetector CT. Radiol Med 2012;117:739-748.

71. Raza A, Sood GK. Hepatocellular carcinoma review: current treatment, and evidence-based medicine. World J Gastroenterol 2014;20:4115-4127.

72. Sala M, Llovet JM, Vilana R, Bianchi L, Sole M, Ayuso C, et al. Initial response to percutaneous ablation predicts survival in patients with hepatocellular carcinoma. Hepatology 2004;40:1352-1360.

73. Bartolotta TV, Taibbi A, Midiri M, De Maria M. Hepatocellular cancer response to radiofrequency tumor ablation: contrast-enhanced ultrasound. Abdom Imaging 2008;33:501-511.

74. Leen E, Kumar S, Khan SA, Low G, Ong KO, Tait P, et al. Contrastenhanced $3 D$ ultrasound in the radiofrequency ablation of liver tumors. World J Gastroenterol 2009;15:289-299.

75. Bartolotta TV, Taibbi A, Matranga D, Midiri M, Lagalla R. 3D versus $2 \mathrm{D}$ contrast-enhanced sonography in the evaluation of therapeutic response of hepatocellular carcinoma after locoregional therapies: preliminary findings. Radiol Med 2015;120:695-704.

76. Ogren M, Bergqvist D, Bjorck M, Acosta S, Eriksson H, Sternby NH. Portal vein thrombosis: prevalence, patient characteristics and lifetime risk: a population study based on 23,796 consecutive autopsies. World J Gastroenterol 2006;12:2115-2119.

77. Raza SA, Jang HJ, Kim TK. Differentiating malignant from benign thrombosis in hepatocellular carcinoma: contrast-enhanced ultrasound. Abdom Imaging 2014;39:153-161.

78. Bartolotta TV, Taibbi A, Picone D, Anastasi A, Midiri M, Lagalla R. Detection of liver metastases in cancer patients with geographic fatty infiltration of the liver: the added value of contrast-enhanced sonography. Ultrasonography 2017;36:160-169.

79. Chung YE, Kim KW. Contrast-enhanced ultrasonography: advance and current status in abdominal imaging. Ultrasonography 2015;34:3-18.

80. Nolsoe CP, Lorentzen T. International guidelines for contrastenhanced ultrasonography: ultrasound imaging in the new millennium. Ultrasonography 2016;35:89-103.

81. Kim TK, Khalili K, Jang HJ. Local ablation therapy with contrastenhanced ultrasonography for hepatocellular carcinoma: a practical review. Ultrasonography 2015;34:235-245.

82. Cassinotto C, Aube C, Dohan A. Diagnosis of hepatocellular carcinoma: an update on international guidelines. Diagn Interv Imaging 2017;98:379-391.

83. Ferraioli G, Meloni MF. Contrast-enhanced ultrasonography of the liver using SonoVue. Ultrasonography 2018;37:25-35. 